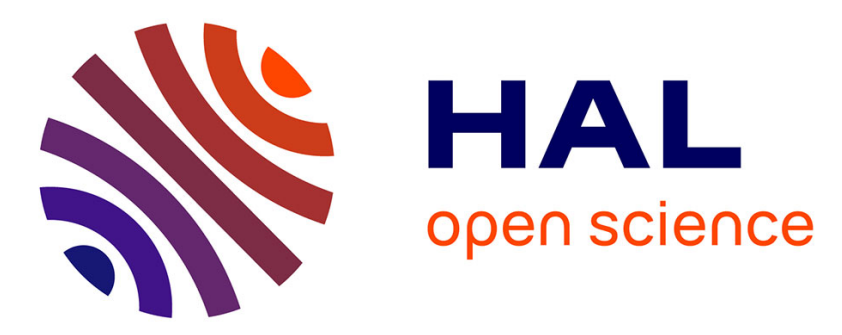

\title{
Ciprofloxacin-Loaded Inorganic--Organic Composite Microparticles To Treat Bacterial Lung Infection
}

Frederic Tewes, Julien Brillault, Barbara Lamy, Peter O 'Connell, Jean-Christophe Olivier, William Couet, Anne Marie Healy

\section{- To cite this version:}

Frederic Tewes, Julien Brillault, Barbara Lamy, Peter O 'Connell, Jean-Christophe Olivier, et al.. Ciprofloxacin-Loaded Inorganic-Organic Composite Microparticles To Treat Bacterial Lung Infection. Molecular Pharmaceutics, 2015, 13 ((1)), pp.100-112. 10.1021/acs.molpharmaceut.5b00543 . inserm01373710

\section{HAL Id: inserm-01373710 https://www.hal.inserm.fr/inserm-01373710}

Submitted on 29 Sep 2016

HAL is a multi-disciplinary open access archive for the deposit and dissemination of scientific research documents, whether they are published or not. The documents may come from teaching and research institutions in France or abroad, or from public or private research centers.
L'archive ouverte pluridisciplinaire $\mathbf{H A L}$, est destinée au dépôt et à la diffusion de documents scientifiques de niveau recherche, publiés ou non, émanant des établissements d'enseignement et de recherche français ou étrangers, des laboratoires publics ou privés. 


\section{Ciprofloxacin-loaded inorganic-organic composite microparticles to treat bacterial lung infection}

Frederic Tewes ${ }^{1,2^{*}}$, Julien Brillault ${ }^{1}$, Barbara Lamy ${ }^{1}$, Peter O’Connell ${ }^{2}$, Jean-Christophe Olivier $^{1}$, William Couet ${ }^{1}$ and Anne Marie Healy ${ }^{2}$.

1: INSERM U 1070, Pôle Biologie-Santé, Université de Poitiers, Faculté de Médecine \& Pharmacie, 1 rue Georges Bonnet, 86022 Poitiers Cedex, France.

2: School of Pharmacy and Pharmaceutical Sciences, University of Dublin, Trinity College Dublin, Dublin 2, Ireland

* To whom correspondence should be sent. Ph.: 0033549454 929, Fax: 0033549454378 e-mail: ftewes@univ-poitiers.fr

Keywords: Pulmonary delivery; composite particles; amorphous calcium carbonate; controlled permeability; ciprofloxacin. 


\begin{abstract}
Ciprofloxacin (CIP) is an antibiotic that has been clinically trialed for the treatment of lung infections by aerosolisation. However, CIP is rapidly systemically absorbed after lung administration, increasing the risk for subtherapeutic pulmonary concentrations and resistant bacteria selection. In the presence of calcium, CIP forms complexes that reduce its oral absorption. Such complexation may slow down CIP absorption from the lung thereby maintaining high concentration in this tissue. Thus, we developed inhalable calcium-based inorganic-organic composite microparticles to sustain CIP within the lung. The aerodynamics and micromeritic properties of the microparticles were characterized. FTIR and XRD analysis suggest that the inorganic component of the particles comprised amorphous calcium carbonate and amorphous calcium formate, and that CIP and calcium interact in a 1:1 stoichiometry in the particles. CIP was completely released from the microparticles within 7 hours, with profiles showing a slight dependence on $\mathrm{pH}$ (5 and 7.4) compared to the dissolution of pure CIP. Transport studies of CIP across Calu-3 cell monolayers, in the presence of various calcium concentrations, showed a decrease of up to $84 \%$ in CIP apparent permeability. The apparent minimum inhibitory concentration of CIP against $P$. Aeruginosa and $S$. Aureus was not changed in the presence of the same calcium concentration. These results indicate that the designed particles should provide sustained levels of CIP with therapeutic effect in the lung. With these microparticles, it should be possible to control CIP pharmacokinetics within the lung, based on controlled CIP release from the particles and reduced apparent permeability across the epithelial barrier due to the cation-CIP interaction.
\end{abstract}




\section{Introduction}

Several lung diseases such as cystic fibrosis (CF), bronchiectasis or chronic obstructive pulmonary disease (COPD) are prone to chronic lung infections, largely due to $P$. aeruginosa. ${ }^{1,}$ ${ }^{2}$ Pulmonary administration of aerosolized antibiotics is an interesting approach, as it can target the lungs directly and may potentially increase the therapeutic/systemic side effects index. Thus, for some drugs, direct delivery to the target tissue allows high local concentrations to be achieved while administering low doses. This is especially true for antibiotics with a low lungblood barrier permeability, as has been shown for colistin. ${ }^{3,4}$ However; this approach is less interesting for molecules that readily diffuse through the barrier to equilibrate with the blood.

Hence, only antibiotics that have low epithelium barrier permeability, such as tobramycin, colistimethate $\left(0.58 \pm 0.08 \times 10^{-7} \mathrm{~cm} / \mathrm{s}\right)^{3}$ and aztreonam lysine $\left(<0.4 \times 10^{-7} \mathrm{~cm} / \mathrm{s}\right)^{5}$, are currently used by nebulization to treat lung infections. The duration of the nebulization treatment regimen is generally ten to twenty minutes, once or twice a day. This extended, daily treatment method has a negative impact on patient quality of life and treatment compliance. Dry powder inhalation is much more convenient than classic nebulization for this particular application, as it considerably reduces the time for administration of a dose. Tobramycin was approved by the FDA in 2013 to treat lung infection in CF patients via a dry powder inhaler (DPI) ${ }^{6}$ and a colistimethate sodium DPI received European approval in $2012 .^{7}$

The main challenges with drug administration using a DPI are the control of deposition of the powder particles and the drug pharmacokinetics within the lung. The first part of this challenge can be solved by the development of antibiotic-loaded microparticles with suitable aerodynamic properties that can reach the deep lungs when delivered using a DPI. ${ }^{8,} 9$ Importantly, these microparticles can be engineered to control the drug release and adapt it to reach the desired profile of antibiotic concentration in the lung versus time after inhalation. 
Fluoroquinolones (FQs) such as ciprofloxacin (CIP) are antibiotics that are commonly used in $\mathrm{CF}$ patients to treat lung infections by oral administration. ${ }^{10}$ However, FQs show some toxicity when present at high concentration in the blood, ${ }^{11,12}$ and, more importantly, the development of resistant bacteria is facilitated when the concentration at the site of infection, i.e. the lung epithelial lining fluid (ELF), is low. ${ }^{13}$ Thus, an aerosolized form of CIP that could enable high concentrations in the lung to be achieved and, at the same time, a lower plasma concentration, would be of interest.

Aerosolized microparticles of CIP could provide high CIP pulmonary deposition, followed by a suitable release profile to maintain an absence of bacterial regrowth. Phase II clinical studies recently evaluated CIP-loaded liposomes as a once-daily inhalation formulation. ${ }^{14}$ This formulation was well tolerated, and more effective than placebo at reducing $P$. aeruginosa lung load in non-CF bronchiectasis. However, the CIP concentration in the lung was found to decline rapidly after nebulisation, increasing the risk of potentially subtherapeutic concentrations. ${ }^{15}$ In fact, CIP was found to have high lung epithelium apparent permeability (7 $\left.\mathrm{x} 10^{-7} \mathrm{~cm} / \mathrm{s}\right)^{16}$, and a rapid systemic absorption after pulmonary nebulization of CIP solutions was observed in ats $^{17}$ and mice. ${ }^{18}$ Therefore, a means of maintaining CIP concentrations within the lung is thus desirable if the pulmonary route of administration is to be successful.

Recent phase I and II clinical studies have also shown encouraging data after inhalation of CIP powder using a DPI. ${ }^{19,20}$ The powder was well tolerated by CF patients, and reduced side effects compared to oral and intravenous CIP administration were observed. ${ }^{15,} 19,20 \mathrm{CIP}$ concentration measured in induced sputum 45 min after the last dose administered was 100fold higher than the MIC for P. aeruginos $a{ }^{15}$ However, as reported by Stass et al. ${ }^{15}$, the pharmacokinetic properties of CIP delivered by DPI were characterized by rapid pulmonary absorption of CIP into the plasma. In this article the authors indicated that the drug concentration in induced sputum declined rapidly 45 min after the last dose was administered, 
increasing the risk for potentially subtherapeutic trough levels that cannot be easily compensated by inhalation of higher doses. ${ }^{15}$ Because an increased frequency of dosing did not seem to influence tolerability to CIP or to produce drug accumulation, the authors suggested that active lung CIP concentrations should be best maintained by optimizing the frequency of dosing.

An alternative approach to maintaining active lung CIP concentrations could be to reduce its apparent lung-blood barrier permeability in order to decrease its pulmonary absorption into the plasma. CIP can form complexes with multivalent cations $\left(\mathrm{Ca}^{2+}, \mathrm{Mg}^{2+}, \ldots\right)$ resulting in the formation of a larger (since multivalent stoichiometry can be formed), and often ionized (cationic) molecular structure. ${ }^{21-23}$ This complexation results in a slower diffusion through the epithelium, as has been demonstrated in the intestine. ${ }^{24,25}$ For example, the presence of $\mathrm{Ca}^{2+}$ and $\mathrm{Al}^{3+}$ significantly reduces the intestinal absorption of CIP when taken orally, by $60 \%$ and $100 \%$, respectively. ${ }^{26}$ The effect of these cation-FQ interactions has only been cursorily studied in terms of pulmonary absorption ${ }^{27}$ and, while it proves a limitation in terms of oral delivery, it could be potentially exploited to slow down CIP absorption through the lung. Therefore, we hypothesized that a calcium-based composite particle formulation could be used to deliver CIP to the lung by a DPI and control CIP pharmacokinetics within the lung, due to controlled release and reduced apparent permeability owing to a Ca-CIP interaction, while maintaining antibacterial activity.

\section{Experimental}

Ciprofloxacin (CIP) powder (purity $\geq 98,0 \%$ ), high molecular weight (1.5 to $1.8 \times 10^{6} \mathrm{Da}$ ), hyaluronic acid sodium salt from Streptococcus equi (HA), calcium hydroxide $\mathrm{Ca}(\mathrm{OH})_{2}$ and ammonium carbonate $\left(\mathrm{NH}_{4}\right)_{2} \mathrm{CO}_{3}$ were purchased from Sigma Aldrich (Ireland). Buffer concentrate $\mathrm{pH} 5$ (Titrisol) was purchased from Merck (Germany) and Hank's Balanced Salt Solution (HBSS) was purchased from Gibco (France). Deionised water was produced by a 
Purite Prestige Analyst HP water purification system (Millipore, Carrigtwohill, Ireland). HPLC grade acetonitrile was purchased from Sigma-Aldrich (Ireland).

\subsection{CIP assay}

CIP was assayed using a validated HPLC method with fluorometric detection $\left(\lambda_{\text {excit }} 280 \mathrm{~nm}\right.$; $\left.\lambda_{\text {emi }} 460 \mathrm{~nm}\right)$. The stationary phase was XTerra MS C18 column, $5 \mu \mathrm{m}, 100 \times 2.1 \mathrm{~mm}$ (Waters). The mobile phase (flow rate: $0.25 \mathrm{~mL} / \mathrm{min}$ ) consisted of a 20:80 (v:v) mixture of acetonitrile and water containing $0.1 \%$ formic acid and $0.2 \%$ heptane sulfonic acid. Samples, standards (7 levels with concentration ranging from 1.56 to $50 \mu \mathrm{g} / \mathrm{L})$ and quality controls $(3.12$, 12.5 and $37.5 \mu \mathrm{g} / \mathrm{L})$ prepared in the same solvent were injected $(75 \mu \mathrm{L})$ and eluted over a run time of $6.5 \mathrm{~min}$. The precision and accuracy were less than $15 \%$ for the 3 quality control concentrations.

\subsection{Spray Drying}

A Büchi B-290 Mini Spray Dryer (Büchi, Flawil, Switzerland) was set up as follows: Two aqueous solutions were prepared separately and mixed during the process via a Y-tubing connector feed to the spray dryer. One solution was composed of CIP $(0.2-0.8 \mathrm{~g} / \mathrm{L})$, calcium hydroxide $\left(\mathrm{Ca}(\mathrm{OH})_{2}-0.8 \mathrm{~g} / \mathrm{L}\right)$, hyaluronate $(\mathrm{HA}-0.4 \mathrm{~g} / \mathrm{L})$, and $0.1(\mathrm{v} / \mathrm{v}) \%$ formic acid $(\mathrm{HCOOH})$ which was used to increase the $\mathrm{Ca}(\mathrm{OH})_{2}$ solubility. In the presence of $\mathrm{Ca}(\mathrm{OH})_{2}$ the CIP apparent solubility was increased and a concentration as high as $0.8 \mathrm{~g} / \mathrm{L}$ was reached, in comparison to the CIP solubility at $20^{\circ} \mathrm{C}$ of $0.07 \mathrm{~g} / \mathrm{L} \cdot{ }^{28}$ The second solution was made of $2.4 \mathrm{~g} / \mathrm{L}$ ammonium carbonate $\left(\mathrm{NH}_{4}\right)_{2} \mathrm{CO}_{3}$. The spray dryer was operated in an open-cycle sucking mode using a 2-fluid nozzle to disperse the mixed solutions (peristaltic pump was set at $30 \%$, pumping the 2 solutions at the same flow rate before their mixing in the Y-tubing connector) in the same direction as the flow of hot drying air (flowing at $630 \mathrm{~L} / \mathrm{min}$ ) and as the spraying air (flowing at $15 \mathrm{~L} / \mathrm{min}$ ). Inlet temperature was $120^{\circ} \mathrm{C}$. These conditions resulted in an outlet temperature ranging from 47 to $57^{\circ} \mathrm{C}$. 


\subsection{Characterisation of materials}

Scanning Electron Microscopy (SEM) of samples was undertaken using a Tescan Mira XMU (Tescan s.r.o., Czech Republic) electron microscope. The samples were fixed on aluminium stubs using double-sided adhesive tabs and sputter-coated with a $10 \mathrm{~nm}$-thick gold film. Primary electrons were focused and accelerated under a voltage of $5 \mathrm{kV}$ in the high vacuum mode (chamber vacuum $9 \times 10^{-3} \mathrm{~Pa}$ ). Magnified images (x10k and $\times 20 \mathrm{k}$ ) of the samples having a maximal resolution of $2.5 \mathrm{~nm}$ were formed from the collection of secondary electrons.

Powder X-ray Diffraction (XRD) measurements were conducted on samples placed in a low background silicon holder, using a Rigaku Miniflex II desktop X-ray diffractometer (Rigaku, Tokyo, Japan). The samples were scanned over a range of $10-55^{\circ} 2 \theta$ at a step size of $0.05^{\circ} / \mathrm{s}$.

Attenuated total reflectance (ATR)-FTIR measurements were performed on powders placed on a wedged diamond crystal using a Spectrum 400FT spectrometer (PerkinElmer, Ireland). For each spectrum, 32-scan interferograms were collected with $4 \mathrm{~cm}^{-1}$ resolution. Clean crystal surface was used as reference. Background spectra were subtracted from sample spectra.

Dynamic Vapour Sorption (DVS) experiments were performed on a DVS-1 (SMS Ltd., London, UK) as previously described ${ }^{29}$. The DVS-1 measures the vapour mass change with a resolution of $\pm 0.1 \mu \mathrm{g}$. The samples maintained at $25.0 \pm 0.1^{\circ} \mathrm{C}$ were exposed to the following $\%$ of relative humidity $(\mathrm{RH})$ profile: $0,3,5,10 \%$, then to $90 \%$ in $10 \%$ steps and the reverse for desorption. At each stage, the sample mass was allowed to reach equilibrium, defined as $\mathrm{dm} / \mathrm{dt}$ $\leq 0.002 \mathrm{mg} / \mathrm{min}$ over $10 \mathrm{~min}$, before the $\mathrm{RH}$ was changed. The amount of water uptake for each RH stage was expressed as a \% of the dry sample mass $\left(\mathrm{m}_{0}\right)$.

The volume-weighted geometric particle size distributions (PSD) were determined by laser diffraction using a Malvern Mastersizer 2000 (Malvern Instruments Ltd. Worcestershire, UK) with the Scirocco 2000 dry powder feeder to disperse the particles. The dispersive air pressure used was 2 bar. Samples were run at a vibration feed rate of $50 \%$. Analyses were undertaken 
using a real part refractive index of 1.572 and an absorption part of 0.01 . Results presented are the average of three determinations.

The specific surface area of the samples purged under $\mathrm{N}_{2}$ overnight at $30{ }^{\circ} \mathrm{C}$ was determined by the $\mathrm{N}_{2}$ adsorption B.E.T. multipoint method, with 6 points in the relative pressure range of 0.1-0.3, using a Micromeritics Gemini 2835c (SMS Ltd., London, UK). Results presented are the average of three determinations.

The calcium content of the particles was assayed using an inductively coupled plasma optical emission spectrometer ICP-OES (Perkin Elmer Optima 2000DV). Three measurements were made at $317.933 \mathrm{~nm}$ and averaged.

The aerodynamic particle size distribution was measured using a next generation cascade impactor (NGI, Copley Scientific). The air flow rate was adjusted to $60 \mathrm{~L} / \mathrm{min}$ and the time of aspiration was adjusted to 4 seconds by using a critical flow controller (TPK 2000, Copley Scientific) to obtain $4 \mathrm{~L}$ of aspiration. In this condition critical sonic flow was assured (P3/P2 < 0.5 ) and the flow rate was assumed to be stable. The inhaler (Handihaler ${ }^{\circledR}$, Boeringher Ingelheim) was filled with a gelatin $\mathrm{n}^{\mathrm{o}} 3$ capsule loaded with $10 \pm 2 \mathrm{mg}$ of powder $(\mathrm{n}=3)$. After inhaler actuation, particle deposition on the NGI was determined by CIP assay as described above. The amount of particles with aerodynamic diameter $\leq 5.0 \mu \mathrm{m}$, expressed as a percentage of the emitted recovered dose, was considered as the fine particle fraction (FPF). The mass median aerodynamic diameter (MMAD) and FPF were calculated as previously described. ${ }^{30}$

Dissolution/release studies were performed by measuring the quantity of CIP crossing through a dialysis membrane with a nominal cut-off of 12,000 (Cellu Sep; Membrane Filtration Products; USA). Samples containing around $4 \mathrm{mg}$ of CIP were loaded in the dialysis bag and dispersed in $5 \mathrm{~mL}$ of dissolving medium (HBSS pH 7.4 to simulate the epithelial lining fluid (ELF) or acetate buffer $\mathrm{pH} 5$ simulating the phagolysosome $\mathrm{pH}$ ). Bags were then placed in a sealed bottle containing $195 \mathrm{~mL}$ of the same dissolving medium. Bottles were maintained at 
$37^{\circ} \mathrm{C}$ and shaken at $300 \mathrm{rpm}$ (VWR Incubating Mini Orbital Shaker), while samples (1 mL) from the external side of the bag were taken at different time points and replaced by fresh media. Samples were kept at $4{ }^{\circ} \mathrm{C}$ prior to HPLC assay. These experiments were performed under sink conditions, i.e. no more than $10 \%$ of CIP solubility $\left(200 \mathrm{mg} / \mathrm{L}\right.$ at $\mathrm{pH}=7$ and at $\left.37^{\circ} \mathrm{C}\right)$ 31 was reached after complete dissolution/release of the CIP. Analysis was performed in triplicate for each sample and results averaged. CIP release was modelled using the Higuchi equation, $\mathrm{M}_{\mathrm{t}} / \mathrm{M}_{\infty}=\mathrm{kt}^{0.5}$ and the power law, $\mathrm{M}_{\mathrm{t}} / \mathrm{M}_{\infty}=\mathrm{kt}^{\mathrm{n}}$, for the time range 0-3h. In these equations, $\mathrm{M}_{\mathrm{t}}$ and $\mathrm{M}_{\infty}$ are the absolute cumulative amount of drug released at time $\mathrm{t}$ and infinite time, respectively; $\mathrm{k}$ is a constant incorporating structural and geometric characteristics of the particle, and $\mathrm{n}$ is the release exponent, indicative of the mechanism of drug release. ${ }^{32}$ Over this time period, less than $80 \%$ of the CIP was released in both cases, justifying the use of both these equations, which are short time approximations of complex exact relationships.

\subsection{CIP transepithelial transport across Calu-3 cell monolayers}

Calu-3 cells (American Type Culture Collection, Rockville, USA) were cultured in Dulbecco's modified Eagle's medium-Ham's F12 medium (1:1) supplemented with L-glutamine (2 mM), fetal calf serum $(10 \% \mathrm{v} / \mathrm{v})$, at $37^{\circ} \mathrm{C}$ and $5 \%$ of $\mathrm{CO}_{2}$ in plastic culture flasks of $75 \mathrm{~cm}^{2}$ (Nunc, Roskilde, Denmark). The medium was replaced every 2-3 days. Cell monolayers were obtained by seeding Calu-3 cells $\left(5 \times 10^{5}\right.$ cells $\left./ \mathrm{cm}^{2}\right)$ at passages 22 to 50 onto Transwell ${ }^{\circledR}$ polyester membranes having pore size of $0.4 \mu \mathrm{m}$ in 12 well plates (Corning, Netherlands), and culturing under air-interface conditions. The volume of media in the basolateral compartment was 1.5 $\mathrm{mL}$ and was replaced every other day. After 15 days of culture, transport experiments were carried out in Hank's buffered salt solution (HBSS) buffered with HEPES in the apical (AP) to basolateral (BL) direction as previously described. ${ }^{33}$ Monolayers were first washed and equilibrated with the buffer for 30 min with $1.5 \mathrm{~mL}$ in the $\mathrm{BL}$ compartment and $0.5 \mathrm{~mL}$ in the AP compartment. The AP compartment was then refilled with $0.5 \mathrm{~mL}$ of the test solutions and 
plates were incubated at $37^{\circ} \mathrm{C}$. Test solutions were made of CIP at $0.0165 \mathrm{~g} / \mathrm{L}(50 \mu \mathrm{M})$ and various calcium concentrations $(6,4,2,0.4,0.2,0 \mathrm{~g} / \mathrm{L})$ in the HBSS - HEPES buffer. After 60 min, samples were taken from the BL compartment and kept at $-20^{\circ} \mathrm{C}$ prior to HPLC analysis. Following the transport study, a control for monolayer integrity was performed by measuring the fluorescein apparent permeability. ${ }^{33}$ The monolayers were rinsed, fresh HBSS was added to the BL side, and HBSS containing fluorescein $(10 \mu \mathrm{g} / \mathrm{mL})$ was added to the AP side. The inserts were incubated and samples were taken after $60 \mathrm{~min}$ and analysed with a fluorescence plate reader. The threshold apparent permeability (Papp) of $0.7 \times 10^{-6} \mathrm{~cm} . \mathrm{s}^{-1}$ for fluorescein was retained for the monolayer integrity rejection parameter for all experiments. ${ }^{34}$ This corresponds to less than $1 \%$ of the initial amount in the AP compartment.

\subsection{Antimicrobial apparent activity of CIP}

The effect of calcium concentration change on the CIP antibacterial activity was assessed by measuring the CIP minimum inhibitory concentration (MIC) against $P$. aeruginosa PAO1 (CIP 104116, Institut Pasteur, Paris, France) and S. aureus (ATCC 29213). Bacteria were isolated from frozen stock by growing them on Mueller-Hinton agar for 24 hours at $37^{\circ} \mathrm{C}$. The MIC test was performed by dilution in 96-well microdilution plates in Mueller-Hinton broth (MHB) adjusted for calcium and magnesium ions, usually used for quantitative susceptibility testing of bacteria with a variety of antimicrobial agent. Prior to MIC testing, the strains were grown to logarithm phase in fresh MHB for 2-3 hours, then adjusted to 0.5 McFarland standards. The adjusted cultures were diluted 100-times in MHB containing various calcium concentrations (4, $2,0.8,0.4,0.2,0.08,0 \mathrm{~g} / \mathrm{L})$. These solutions were prepared from a calcium chloride stock solution of $147 \mathrm{~g} / \mathrm{L}(1 \mathrm{M})$ in MHB. Then, for each calcium solution, various solutions having different CIP concentrations $(8,4,2,1,0.5,0.25,0.125,0.063,0.031,0 \mathrm{mg} / \mathrm{L})$, for the same calcium concentration, were obtained by a two-fold serial dilution using a CIP stock solution at $800 \mathrm{mg} / \mathrm{L}$ in MHB. The growth of bacterial cultures at $37^{\circ} \mathrm{C}$ was determined after 18 and 24 
hours by monitoring the optical density of the culture at $600 \mathrm{~nm}$ using a plate reader (VarioskanFlash, Thermo Scientific, France). Controls without bacteria were made to check the absence of contamination of MHB and to evaluate the effect of calcium on the absorbance reading at $600 \mathrm{~nm}$. Controls without CIP were made to assess the effect of calcium on bacterial growth.

\section{Results and Discussion}

The aim of this study was to develop an inhalable dry powder formulation of CIP which would allow the concentration of CIP in the pulmonary ELF to be controlled, in order to provide a more efficient therapeutic effect against extracellular bacteria pathogens, such as $P$. Aeruginosa. Our hypothesis is that this could be achieved by controlling CIP release from inhaled particles and, more importantly, by simultaneously slowing down CIP absorption across the lung-blood barrier by means of calcium-CIP interaction. In fact, CIP is rapidly systemically absorbed from the lung after pulmonary administration of pure $\mathrm{CIP}^{15,17,18}$ and a pharmaceutical approach may be used to sustain the presence of CIP in the lung. 

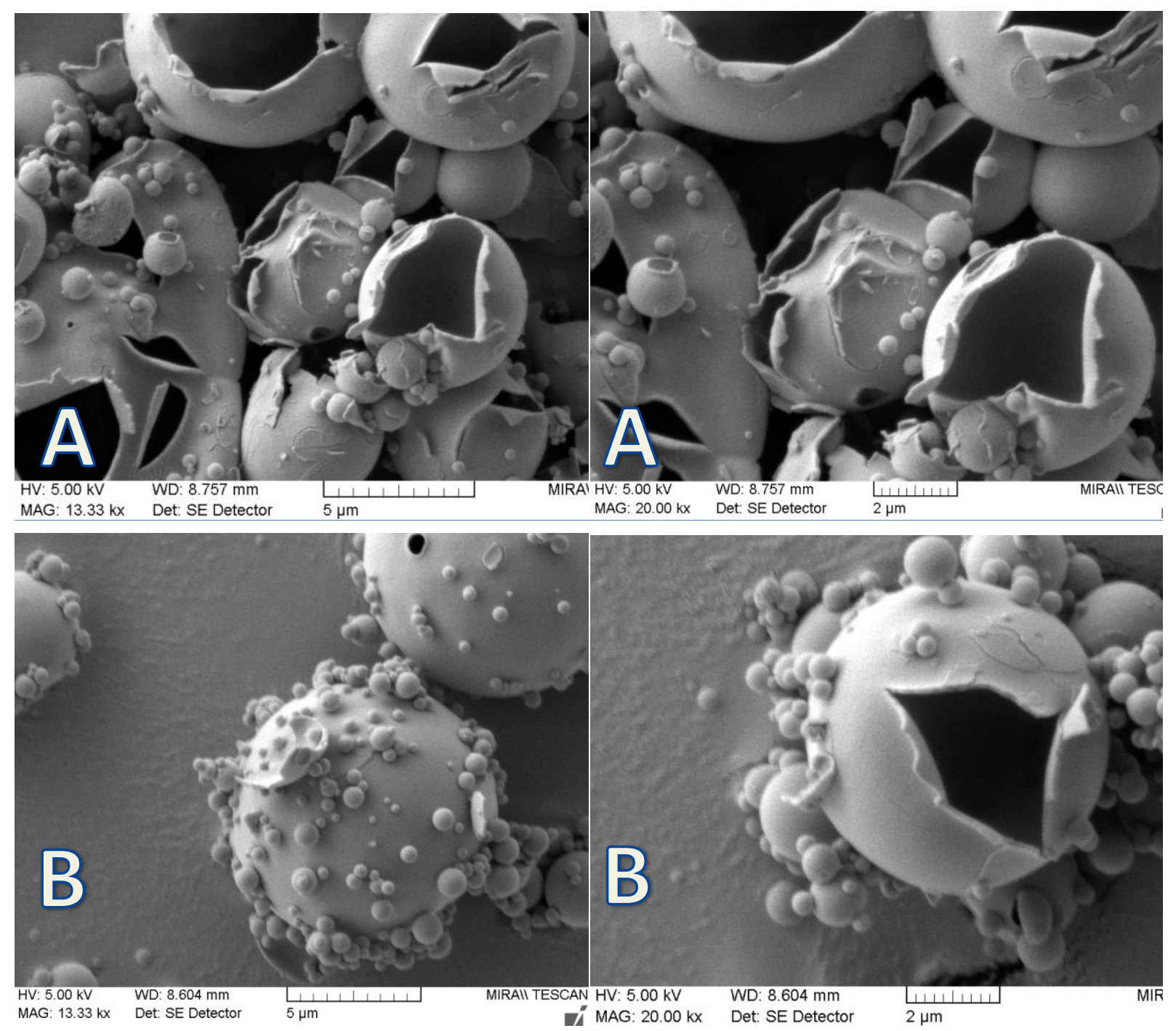

Figure 1: SEM micrographs of CIP-loaded composite particles formulated with various CIP loading A) CIP1, B) CIP3. The samples were coated with a $10 \mathrm{~nm}$-thick gold film. Primary electrons were accelerated under a voltage of $5 \mathrm{kV}$. Images were formed from the collection of secondary electrons.

Light, shell-like microparticles (Fig. 1) were formulated by spray drying a mix of two solutions, based on a calcium carbonate mineralisation bio-inspired process. One of the solutions contained $\left(\mathrm{NH}_{4}\right)_{2} \mathrm{CO}_{3}$ and the other contained $\mathrm{CIP}$, calcium and sodium hyaluronate (HA, Table 1). In this formulation, calcium and carbonate ions react to form poorly soluble calcium carbonate just before being sprayed. High molecular weight HA was added to act as a matrix/template and control the shape of the calcium minerals, resulting in microspheres. In fact, negatively charged carboxylic groups from $\mathrm{HA}$ can be used to interact with $\mathrm{Ca}^{2+}$ and control the nucleation of $\mathrm{CaCO}_{3} \cdot{ }^{35,36}$ Furthermore, high molecular weight $\mathrm{HA}\left(\mathrm{Mw}>1 \times 10^{6}\right.$ 
Da) is part of the extracellular lung matrix and has already been investigated as an inhalable therapeutic agent for lung diseases. ${ }^{37,38}$ For example, inhaled HA prevents the side effects of hypertonic saline inhalation alone, which is used to treat bronchiolitis and patients with cystic fibrosis. $^{37}$

Table 1: Composition and physical properties of various $\mathrm{Ca} / \mathrm{HA}$ composite particles.

\begin{tabular}{|c|c|c|c|c|c|c|c|c|}
\hline & \multicolumn{4}{|c|}{ Feed solution composition } & \multicolumn{2}{c|}{ Loading } & $\begin{array}{c}\text { Ca/CIP } \\
\text { ratio }\end{array}$ \\
\hline CODE & $\begin{array}{c}\mathrm{CIP} \\
(\mathrm{g} / \mathrm{L})\end{array}$ & $\begin{array}{c}\mathrm{HA}^{-}, \mathrm{Na}^{+} \\
(\mathrm{g} / \mathrm{L})\end{array}$ & $\begin{array}{c}\left(\mathrm{NH}_{4}\right)_{2} \mathrm{CO}_{3} \\
(\mathrm{~g} / \mathrm{L})\end{array}$ & $\begin{array}{c}\mathrm{Ca}(\mathrm{OH})_{2} \\
(\mathrm{~g} / \mathrm{L})\end{array}$ & $\begin{array}{c}\mathrm{HCOOH} \\
\%(\mathrm{v} / \mathrm{v})\end{array}$ & $\begin{array}{c}\mathrm{CIP} \\
\%(\mathrm{w} / \mathrm{w})\end{array}$ & $\begin{array}{c}\mathrm{Ca} \\
\%(\mathrm{w} / \mathrm{w})\end{array}$ & molar \\
\hline Unloaded & 0 & 0.4 & 2.4 & 0.8 & 0.1 & - & $57.3 \pm 4.6$ & $\mathrm{ND}$ \\
\hline $\mathrm{CIP} 1$ & 0.2 & 0.4 & 2.4 & 0.8 & 0.1 & $14.7 \pm 0.2$ & $\mathrm{ND}$ & $\mathrm{ND}$ \\
\hline CIP2 & 0.4 & 0.4 & 2.4 & 0.8 & 0.1 & $25.1 \pm 0.4$ & $\mathrm{ND}$ & $\mathrm{ND}$ \\
\hline CIP3 & 0.8 & 0.4 & 2.4 & 0.8 & 0.1 & $35.4 \pm 0.6$ & $14.8 \pm 0.2$ & 3.5 \\
\hline
\end{tabular}

(ND: not determined)

The solid state characteristics of the spray dried powders were first analysed by powder XRD (Fig. 2). The pure CIP (raw material) XRD pattern displayed intense and narrow diffraction peaks, typical of a crystalline compound (Fig. 2A - curve 5). CIP can exist in two crystalline forms, one a hydrate and one a more soluble anhydrous form. ${ }^{39}$ The XRD pattern of the CIP used in this study corresponds to the anhydrous form. ${ }^{40}$ The diffraction peaks observed on the different XRD patterns of the spray dried formulations were broad and of low intensity, suggesting the absence of an XRD crystalline structure, or a low degree of crystallinity in the formulation due either to the presence of small quantities of crystalline structure, or crystalline structures of small size. The XRD pattern of the unloaded particles (Fig. 2A - curve 1) had low intensity diffraction peaks at 24.9 and $27.12 \theta^{\circ}$, characteristic of calcium carbonate $\left(\mathrm{CaCO}_{3}\right)$ crystallized in the metastable vaterite polymorph, ${ }^{41}$ and peaks at 16 and $26.320^{\circ}$ which are specific for calcium formate $\left(\mathrm{Ca}(\mathrm{HCOO})_{2}\right) .{ }^{42}$ The presence of $\mathrm{CaCO}_{3}$ resulted from the reaction between $\mathrm{Ca}^{2+}$ and $\mathrm{CO}_{3}{ }^{2-}$. Calcium carbonate is a pharmaceutical excipient generally regarded as safe by the regulatory agencies and which has shown low toxicity when inhaled in the form of microparticles. ${ }^{43}$ Also, dry powder therapy based on the inhalation of calcium salts 
(PUR118), demonstrated anti-inflammatory efficacy in phase $1 \mathrm{~b}$ trial with COPD patients. ${ }^{44}$ The calcium formate resulted from the reaction between $\mathrm{Ca}^{2+}$ and $\mathrm{HCOOH}$. Calcium formate is a water-soluble salt of low toxicity which is used as a food additive and may also be used as a dietary calcium supplement. The CIP loading of the particles influenced the XRD patterns obtained. At a low loading (14.7\% - CIP1, Table 1) peaks specific to calcium formate prevailed (Fig. 2a - diffractogram B). An increase in CIP loading (35.4\% - CIP3, Table 1) resulted in the disappearance of Bragg peaks on the XRD pattern, demonstrating the XRD amorphous nature of the formulation.
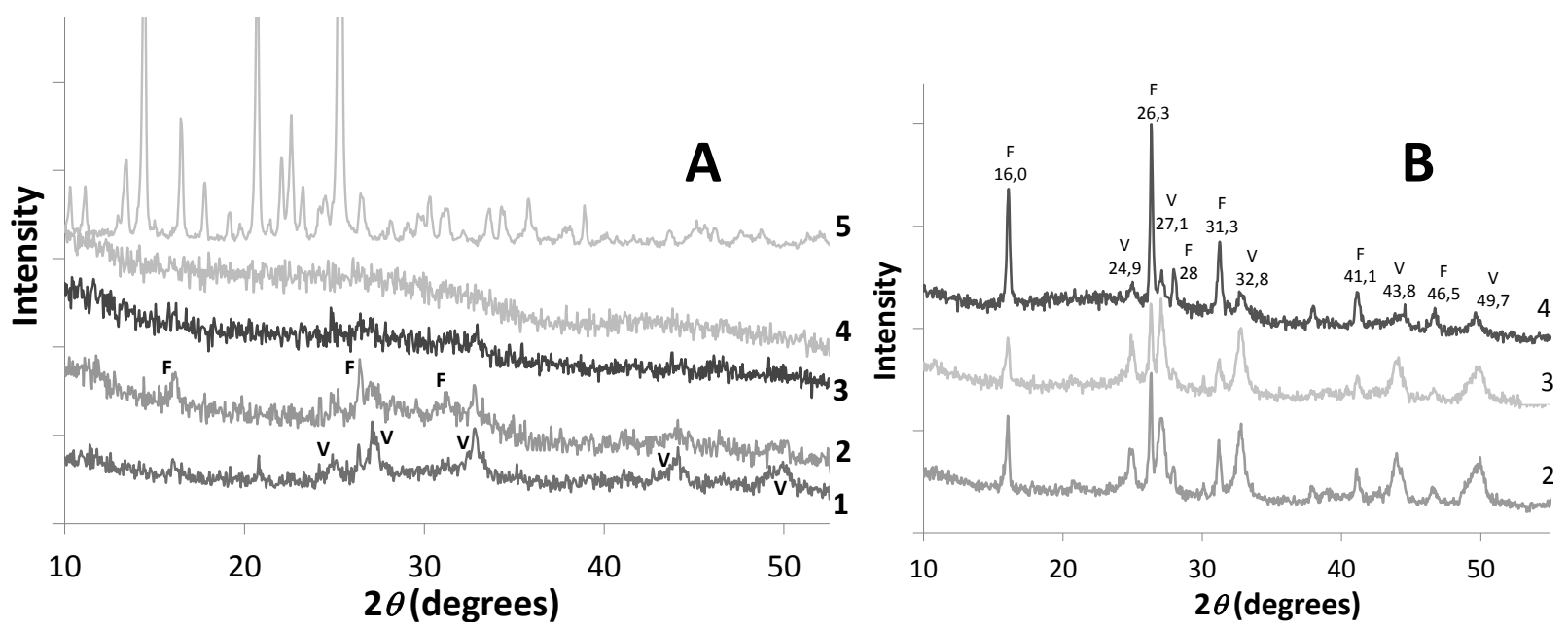

Figure 2: XRD patterns of CIP-loaded formulations - A) after spray drying (1) unloaded particles, (2) CIP1, (3) CIP2, (4) CIP3 and (5) CIP raw material - B) after DVS experiments on (2) CIP1, (3) CIP2 and (4) CIP3. Herein, "F" denotes calcium formate peaks position and "V" denotes vaterite peaks position. A relative intensity plot of vaterite and calcium formate is presented in supplementary materials (Figure S1).

FTIR spectroscopy was used to further investigate the chemical nature of the particles (Fig. 2). The spectrum of pure CIP raw material (Fig. $3-$ E) showed strong bands at $1615 \mathrm{~cm}^{-1}$, which may be assigned to the stretching of the carbonyl ring, and bands at $1588 \mathrm{~cm}^{-1}$ and $1374 \mathrm{~cm}^{-1}$ assigned to asymmetric and symmetric stretching vibrations of the deprotonated carboxylate group, respectively. ${ }^{45}$ The absence of a band around $1710 \mathrm{~cm}^{-1}$ in the CIP raw material spectrum indicated that the CIP carboxylate group was deprotonated. ${ }^{45}$ FTIR spectra recorded for the spray dried powders showed that the CIP carboxylate group was also deprotonated in the particles and thus potentially available to interact with calcium ions. 
All spectra recorded for the spray dried particles presented absorption bands typical of carbonate, suggesting the presence of calcium carbonate. ${ }^{46}$ The unloaded particles were characterized by a broad band of the carbonate bending at $866 \mathrm{~cm}^{-1}$ and a split in the asymmetric stretch of the carbonate ion at 1412 and $1484 \mathrm{~cm}^{-1}$, which is specific to amorphous calcium carbonate (ACC). ${ }^{47,} 48$ As the CIP proportion in the particles increased, bands characteristic of CIP appeared in the spectra, notably at $707 \mathrm{~cm}^{-1}, 822 \mathrm{~cm}^{-1}$, and $866 \mathrm{~cm}^{-1}$. The presence of an absorption band at $866 \mathrm{~cm}^{-1}$ in the CIP spectrum makes it difficult to assign this band to the presence of CIP or ACC in the spray dried formulations. New bands were observed at $748 \mathrm{~cm}^{-1}, 947 \mathrm{~cm}^{-1},\left(1258 \mathrm{~cm}^{-1}, 1268 \mathrm{~cm}^{-1,}\right.$ split band) and $\left(1302 \mathrm{~cm}^{-1}, 1313 \mathrm{~cm}^{-1,}\right.$ split band) for the CIP-loaded particles. These bands, the intensity of which increased with increasing CIP loading, were not present in the spectra of the unloaded particles or the CIP anhydrous form (raw material) and are also absent from the spectra of CIP hydrochloride salt and CIP hexahydrate. ${ }^{45}$ The split bands at $1258,1268 \mathrm{~cm}^{-1}$ and $1302,1313 \mathrm{~cm}^{-1}$ suggested CO stretching vibration in the carboxyl group. These bands were previously identified in the FTIR spectrum of a 1:1 CIP:iron complex ${ }^{49}$ and in the spectrum of 1:1 CIP:copper complex. ${ }^{50}$ Thus, these bands may appear in the FTIR spectra of the formulated particles due to interactions between CIP and calcium, interacting in a 1:1 molar ratio.

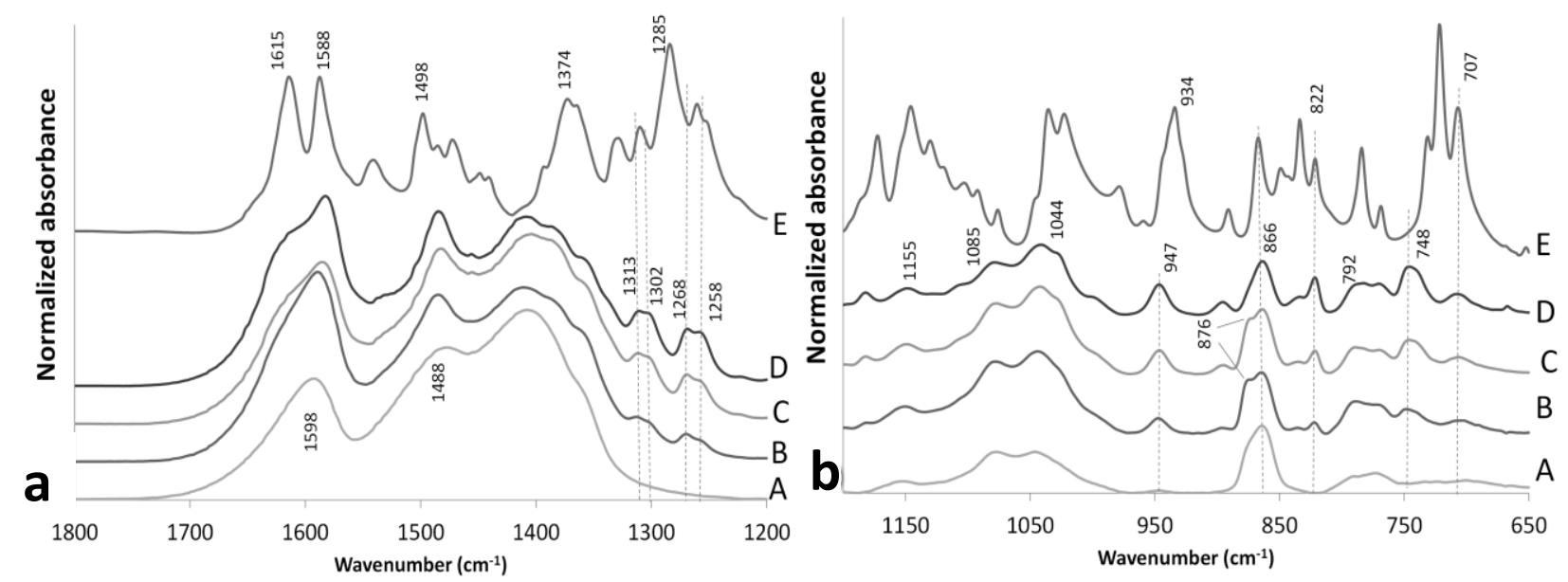

Figure 3: FTIR spectra of composite microparticles formulated at different CIP loading A) unloaded particle, B) CIP1, C) CIP2, D) CIP3, E) CIP. a) From 1800 to $1200 \mathrm{~cm}^{-1}$; b) From 1200 to $650 \mathrm{~cm}^{-1}$. 
Powder X-ray diffraction and FTIR data indicate that the minerals constituting the particles were calcium formate $\left(\mathrm{Ca}(\mathrm{HCOO})_{2}\right)$ and calcium carbonate $\left(\mathrm{CaCO}_{3}\right)$. These minerals were predominantly present in the particles in the XRD amorphous state. The relative proportions of calcium carbonate and calcium formate, and their degree of crystallinity was dependent on the CIP loading. An increase in CIP loading completely amorphised the particles and favoured the formation of calcium formate over calcium carbonate. In all the particles formulated, CIP was solidified in the amorphous state. Thus CIP, potentially interacting with the calcium, could behave as plasticizer, reducing the glass transition temperature of $\mathrm{CaCO}_{3}$ and $\mathrm{Ca}(\mathrm{HCOO})_{2}$, facilitating the formation of the amorphous phase. The presence of amorphous calcium carbonate (ACC), which is the most soluble form of this mineral, suggests potential for a faster absorption and elimination rate than the crystalline forms, as was observed by Meiron et al. ${ }^{51}$ after oral administration. The higher solubility and faster absorption of ACC, compared to the crystalline forms, should prevent any accumulation of solid particles in the lung.

For amorphous solids, interactions with water are fundamental aspects to be studied because they can affect both dissolution properties and physical stability. Water sorption-desorption behaviour of CIP-loaded hybrid microparticles were found to be dependent on the CIP loading. The CIP1 formulation (Fig. 4A - loading of 14.7\%) showed a water mass increase of $20 \mathrm{wt} \%$ with an increase of RH up to $80 \%$, followed by a mass decrease for the 80 and $90 \%$ RH steps. A decrease in mass versus time with increasing RH for amorphous substances generally corresponds to the crystallisation of the material. ${ }^{29}$ In fact, a crystalline material has a lower average surface energy than its corresponding amorphous form. ${ }^{52,53}$ This change in surface properties with an increase in RH resulted in hysteresis in the CIP1 isotherm, with the desorption curve lying below the sorption curve. A similar behaviour was observed for CIP2 (loading of $25.1 \%$ ), but water loss (corresponding to crystallisation) was only observed above 90\% RH. Crystallisation induced by the increase in $\mathrm{RH}$ also resulted in hysteresis in the resultant isotherm (Fig. 4B). The formulation with the highest CIP loading had a different 
behaviour. CIP3 (loading of 35.4\%) water uptake kinetics did not show a mass loss with an increase in RH and the isotherm displayed less hysteresis (Fig. 4C). Evaluation of the solid state nature of the powder formulations was performed by XRD after the DVS experiment (Fig. 2B). XRD diffractograms showed the appearance or an increase in the intensity of the diffraction peaks specific to vaterite and/or to calcium formate. The intensity of peaks specific to calcium formate increased and the intensity of peaks specific to vaterite decreased with an increase in CIP loading in the formulation. Also, in CIP3 (which had the highest CIP loading), the main crystalline structure formed during water sorption was calcium formate (Fig. 2B curve 4). Therefore, the crystallization that occurs in the particles during water sorption corresponds to crystallization of calcium formate and calcium carbonate that are present initially in an amorphous form in the particles. For CIP1 and CIP2, which had XRD peaks corresponding to calcium formate and vaterite of equal intensity after water vapor exposure, this crystallization induced a change in particle surface properties and altered desorption versus sorption properties, which was reflected in the hysteresis observed. For CIP3, which had XRD peaks corresponding mainly to calcium formate, its water affinity did not change and no hysteresis was thus observed. This dynamic water sorption study indicates that the CIP3 formulation is sensitive to high humidity at $25^{\circ} \mathrm{C}$. However, a stability study performed on CIP3 at $4{ }^{\circ} \mathrm{C}$ under both desiccated conditions and $60 \% \mathrm{RH}$ showed that the particles remained amorphous for more than 8 months (supplementary materials - Figure S2). 

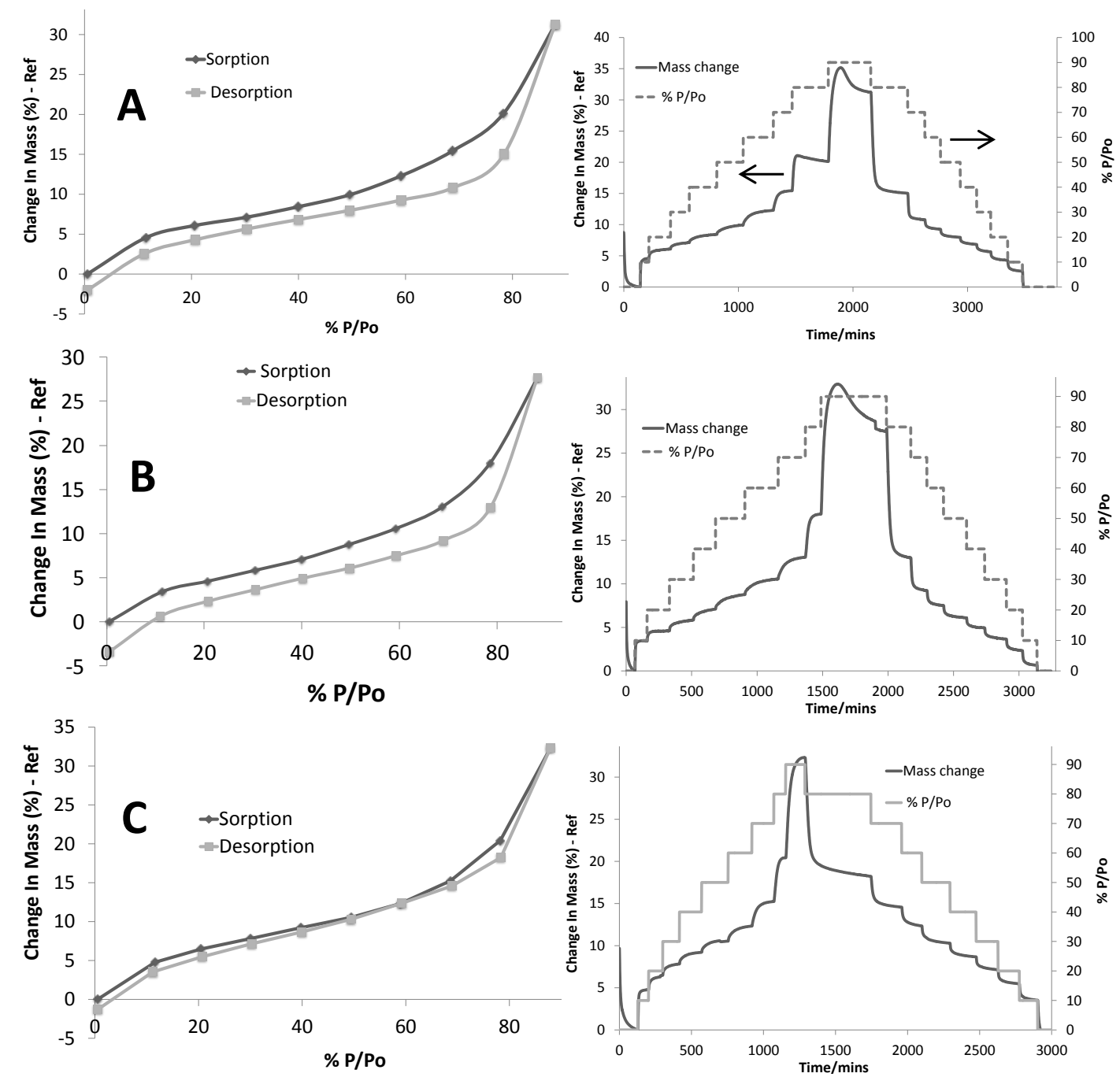

Figure 4: DVS water uptake isotherms (right) and mass change versus time (left) for formulations A) CIP1, B) CIP2 and C) CIP3.

In the case of an inhaled antibiotic, the first requirement is to deliver an appropriate amount of drug to the target site. In order to be able to adapt the CIP dose delivered into the lung to obtain the best therapeutic effect, the CIP loading into the particles needs to be controlled. Inadequate CIP loading could limit the maximal dose that can be administered. Increasing the CIP concentration in the spray dried feed solutions proportionally increased the CIP loading in the particles (Table 1). The range of CIP loadings obtained for the different formulations suggests that the dose may be adapted to suit the clinical need.

Other parameters that control the amount of drug delivered to the lung when using a DPI are the aerodynamic properties of the powder and the amount of powder emitted from the DPI. The 
aerosolization efficiency of a powder is highly dependent on the particle characteristics, such as particle size distribution, shape and surface properties.

Table 2: Micromeritic and aerodynamic properties

\begin{tabular}{|c|c|c|c|c|c|c|c|}
\hline & \multicolumn{4}{|c|}{ Geometric PSD } & \multicolumn{2}{|c|}{ Aerodynamic } & \multirow{2}{*}{$\begin{array}{c}\mathrm{N}_{2} \text { sorption } \\
\text { Specific } \\
\text { Surface } \\
\text { Area }\left(\mathrm{m}^{2} / \mathrm{g}\right)\end{array}$} \\
\hline & $\begin{array}{c}d(0.1) \\
(\mu \mathrm{m})\end{array}$ & $\begin{array}{c}d(0.5) \\
(\mu \mathrm{m})\end{array}$ & $\begin{array}{c}\mathrm{d}(0.9) \\
(\mu \mathrm{m})\end{array}$ & $\begin{array}{l}* \text { Specific } \\
\text { Surface } \\
\text { Area }\left(\mathrm{m}^{2} / \mathrm{g}\right)\end{array}$ & $\begin{array}{c}\text { MMAD } \\
(\mu \mathrm{m})\end{array}$ & GSD & \\
\hline Unloaded & $2.2 \pm 0.1$ & $7.5 \pm 0.2$ & $17.7 \pm 0.3$ & & & & \\
\hline CIP1 & $1.4 \pm 0.1$ & $7.4 \pm 0.2$ & $18.6 \pm 0.4$ & $1.8 \pm 0.1$ & & & $13.66 \pm 0.42$ \\
\hline CIP2 & $2.1 \pm 0.1$ & $9.5 \pm 0.3$ & $28.4 \pm 0.8$ & $1.4 \pm 0.1$ & & & $41.05 \pm 1.11$ \\
\hline CIP3 & $2.8 \pm 0.1$ & $9.4 \pm 0.1$ & $21.4 \pm 0.3$ & $1.1 \pm 0.1$ & $5.00 \pm 0.60$ & $2.46 \pm 0.04$ & $28.75 \pm 0.42$ \\
\hline
\end{tabular}

The volume-weighted particle size distributions were little changed with change in CIP loading (Fig. 5A). Volume median geometric diameters of the particle distributions ranged from $7.4 \pm 0.2 \mu \mathrm{m}$ to $9.5 \pm 0.3 \mu \mathrm{m}$ (Table 2). These diameters would be too high for good particle lung deposition if the particle density was $1 \mathrm{~g} / \mathrm{cm}^{3}$. In fact, to reach the more distal parts of the lung, particles should have an aerodynamic diameter between 1 and $5 \mu \mathrm{m} .{ }^{9}$ Aerodynamic $\left(d_{a}\right)$ and geometric $\left(d_{g}\right)$ diameters are linked by the particle density $\left(\rho_{p}\right)$ and particle shape factor $(\chi)$ according to the following equation $d_{a}=d_{g} \sqrt{\left(\rho_{p} / \rho_{0} \cdot \chi\right)} \cdot{ }^{29}$ Therefore, for particles with a large $d_{g}, \rho_{p}$ should be lower than $1 \mathrm{~g} / \mathrm{cm}^{3}$ and $\chi$ should be higher than 1 in order to decrease $d_{a}$ to the inhalable range. Specific surface area is a good metric indicative of the aerodynamic performance of particles, and an increase in the particle shape factor can be obtained by increasing the specific surface area. ${ }^{54} \mathrm{~A}$ specific surface area may be calculated from the geometric particle size distributions, assuming the particles to be solid spheres with smooth surfaces of the particles; however, surface areas calculated in this manner were low (Table 2). 

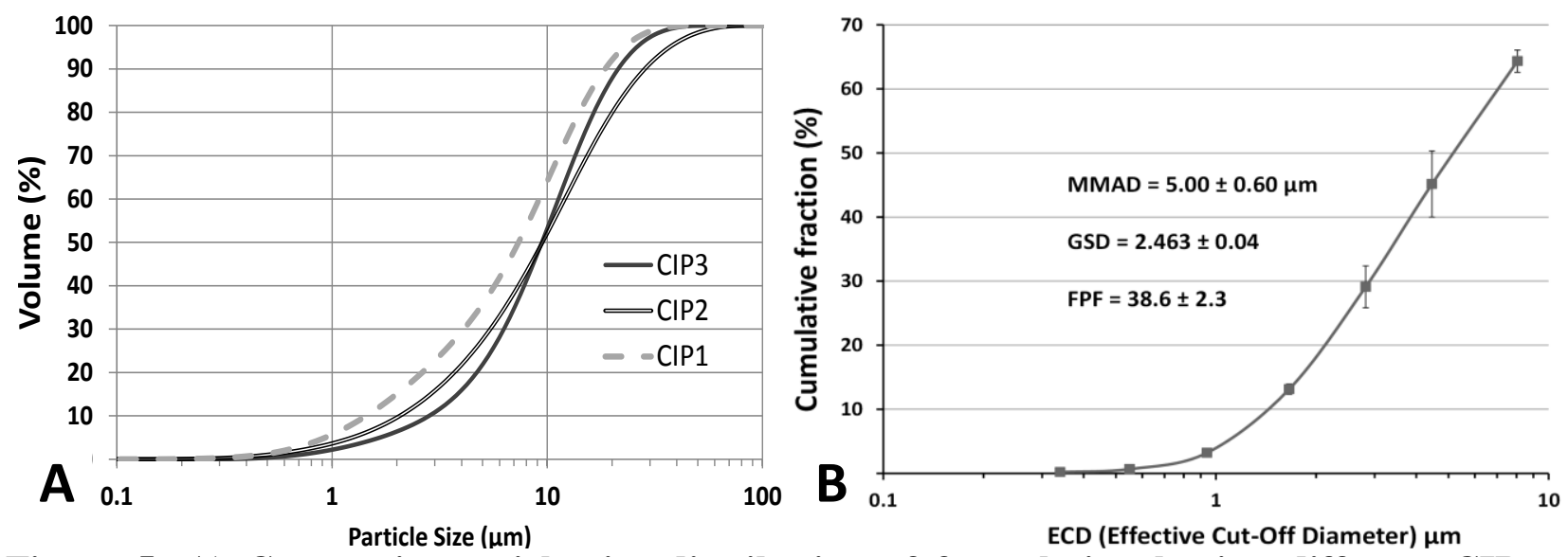

Figure 5: A) Geometric particle size distribution of formulation having different CIP loading. B) Cumulative fraction of the mass of the formulation CIP3 collected on the NGI stages versus the effect cut-off diameter of the stages. Stage by stage deposition representation is added in supplementary materials (Figure S3).

Actual specific surface areas measured by $\mathrm{N}_{2}$ adsorption and using BET theory gave much higher values, ranging from $13.66 \pm 0.42$ to $41.05 \pm 1.11 \mathrm{~m}^{2} / \mathrm{g}$. This difference between specific surface area calculated from particle size and those measured suggests that the particles were porous and/or with textured/wrinkled surfaces. These high values of specific surface area indicate a high particle shape factor and lower $d a$ than $d g$. In fact, the mass median aerodynamic diameter $(\mathrm{MMAD})$ of formulation CIP3 $(5.00 \pm 0.60 \mu \mathrm{m})$ measured using the NGI was significantly lower than the volume median geometric diameter $(9.4 \pm 0.1 \mu \mathrm{m})$ as measured by laser diffraction of the aerosolized powder. This MMAD value is in the range of the breathable fraction of an aerosol, with a MMAD between 1 and $5 \mu \mathrm{m}$, being considered suitable for topical respiratory treatment. However, with this MMAD value, the particles should deposit predominantly in the larger and smaller airways, rather than the alveoli. ${ }^{55}$ An optimization of the formulation to obtain a MMAD around $3 \mu \mathrm{m}$ would be necessary to cover the whole lung. ${ }^{55}$ In this study, the CIP dose delivered to the NGI was around $3.5 \pm 0.4 \mathrm{mg}$ (of the $10 \pm 2 \mathrm{mg}$ of powder per capsule), which is lower than the dose used in a previous clinical study (32.5 mg of CIP in $50 \mathrm{mg}$ of powder). ${ }^{15}$ However, a higher CIP dose could be delivered if a larger amount of powder was loaded in the capsules or if multiple capsules were used. More importantly, a CIP formulation providing a decreased CIP lung-blood barrier 
permeability should allow high solubilized CIP concentrations in ELF to be obtained. In fact the CIP concentration obtained in ELF depends on the amount of drug arriving and dissolving in the small pulmonary ELF volume and to the rate at which it is cleared from the lung.
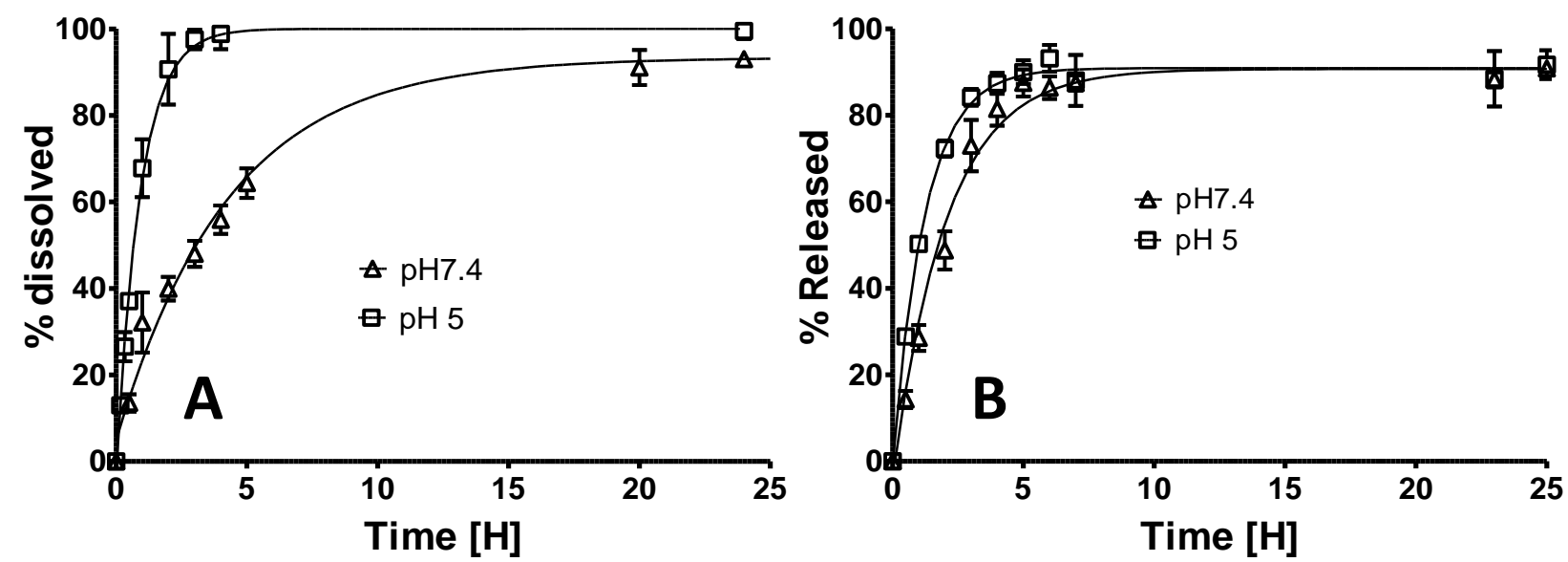

Figure 6: A) CIP dissolution from pure CIP powder and B) CIP release from CIP3 composite particles incubated at $37^{\circ} \mathrm{C}$ for 25 hours. Experiments were performed at $\mathbf{p H}$ 7.4 (open triangle) representing the ELF pH and at pH 5 (open square) representing the phagolysosome $\mathrm{pH}$. Values are average of 3 measurements \pm SD.

Once the particles deposit in the lung, their therapeutic effectiveness depends on the CIP (free and interacting with $\mathrm{Ca}^{2+}$ ) released in the small ELF volume available at the target site. CIP release from the particles was evaluated at $\mathrm{pH} 7.4$ and $\mathrm{pH} 5$, representing the lung ELF $\mathrm{pH}$ and phagolysosome $\mathrm{pH}$, respectively (Fig. 6). CIP dissolution from pure CIP powder (used as control) was dependent on $\mathrm{pH}$ (Fig. 6A). At pH 5, complete CIP dissolution was reached after 3 hours, while CIP complete dissolution was reached after more than 24 hours in buffer $\mathrm{pH}$ 7.4. The free CIP molecule has a carboxylic acid group $(\mathrm{pKa} 1=6.1)$ and a piperazine basic group $(\mathrm{pKa} 2=8.7)$ conferring a $\mathrm{pH}$-dependent solubility and dissolution behaviour. Therefore, CIP can exist in different ionic states, i.e. cationic at acidic $\mathrm{pH}$, zwitterionic at $\mathrm{pH}$ encompassing the $\mathrm{pKa}$, and anionic at basic $\mathrm{pH}$. At $\mathrm{pH} 7.4$, most CIP molecules are in an amphoteric form having a global neutral charge and low solubility, resulting in a low dissolution rate. At $\mathrm{pH}$, around $90 \%$ of CIP is converted to the cationic form, having higher solubility than the amphoteric form, leading to a faster dissolution. Drug release from the dialysis bag can appear slower than other methods as it is affected by the low stirring and convection inside the bag. 
However, this method was able to discriminate between CIP dissolution profiles obtained at $\mathrm{pH}$ 5 and $\mathrm{pH}$ 7.4. No official in vitro dissolution method exists for inhaled powders and the small amount of ELF in the lung makes it extremely difficult to mimic in vitro. Also, the slow fluid motion in the dialysis bag could be a reasonable representation of what happens in the lung. CIP release from composite formulated particles is less sensitive to $\mathrm{pH}$ than CIP dissolution from pure CIP powder (Fig. 6B). Almost complete release was reached (90\%) in 5 and 7 hours at $\mathrm{pH} 5$ and 7.4, respectively. Release rates presented in this study were faster than that observed for a CIP-loaded liposome formulation in HEPES buffered saline, $\mathrm{pH} 7.4^{56}$ but slower than that observed for the same liposome formulation in HEPES buffered saline supplemented with $50 \%$ bovine serum. ${ }^{57,58}$ However, a slow release of CIP, without a decrease of its apparent permeability across the lung-blood barrier is not desirable, as this would lead to low CIP concentration in the pulmonary ELF. In fact, without control of the CIP apparent permeability, CIP slowly released from a formulation deposited in the lung would be rapidly absorbed in the plasma, as occurs after nebulisation of a solution of pure CIP. ${ }^{17,18}$

The lower dependency on $\mathrm{pH}$ of the CIP release from the spray dried formulation compared to the pure CIP dissolution could be due to the initial alkaline microenvironment provided by calcium carbonate dissolution. This alkaline microenvironment should control the ionization state of CIP in the environment of the particles and make CIP release less dependent on the buffer $\mathrm{pH}$. Particles are made of ACC, the most soluble form of calcium carbonate, which should facilitate the control of the micro-environmental basic $\mathrm{pH}$ surrounding the particles. For example, the lower solubility of crystalline calcium carbonate compared to more soluble sodium bicarbonate was found to limit its availability to modulate matrix micro-environmental $\mathrm{pH}^{59}$ Polymeric matrices containing one of these two salts immersed in $\mathrm{pH} 1.5$ dissolution medium showed that sodium bicarbonate induced higher intragel $\mathrm{pH}$ (7.03) compared to crystalline calcium carbonate (5.67). This alkaline microenvironment provided by the particles indicates that $\mathrm{pH}$-independent drug dissolution can be expected within the human ELF, 
reducing CIP release variability and potential biopharmaceutical problems. In fact, various infection sites and diseases can have more acidic $\mathrm{pH}$ than regular ELF, ${ }^{60}$ and the microparticle formulation should release the CIP at the same rate, whatever the infection site. In addition to influencing the CIP solubility, the pH could control the CIP release profile by increasing the solubility of calcium carbonate and particle dissolution rate when the $\mathrm{pH}$ is decreasing. Also, FTIR spectra of the particles suggested interactions between CIP and calcium in a 1:1 ratio. Interaction of one $\mathrm{CIP}^{ \pm}$with one $\mathrm{Ca}^{2+}$ should release a bi-cationic molecular entity " $\mathrm{CIP}^{+}-\mathrm{Ca}^{+}$" that should be more soluble than the zwiterrionic $\mathrm{CIP}^{ \pm}$and could also be responsible for the faster dissolution compared to pure CIP powder.

CIP release was modelled using the Higuchi equation and the power law for the time range 03h. The power law provided the best fit for CIP release at both $\mathrm{pH}$ conditions, with a coefficient of determination higher than 0.98. Parameters $\mathrm{k}$ and $\mathrm{n}$ used for the fitting of the experimental data are described in the Table 3.

Table 3: Estimates for power law parameters determined from the fitting of the release experiments from pure CIP powder and CIP3 formulation.

\begin{tabular}{|c|c|c|c|c|}
\hline \multirow{2}{*}{ CIP3 } & & $\mathrm{k}$ & $\mathrm{n}$ & $\mathrm{R}^{2}$ \\
\cline { 2 - 5 } & $\mathrm{pH} \mathrm{7.4}$ & $28.62 \pm 1.55$ & $0.784 \pm 0.047$ & 0.98 \\
\hline \multirow{3}{*}{ pure CIP } & $\mathrm{pH} \mathrm{5}$ & $47.58 \pm 1.12$ & $0.544 \pm 0.027$ & 0.99 \\
\cline { 2 - 5 } & $\mathrm{pH} \mathrm{7.4}$ & $27.02 \pm 1.45$ & $0.536 \pm 0.042$ & 0.96 \\
\hline & $\mathrm{pH} \mathrm{5}$ & $57.17 \pm 2.14$ & $0.555 \pm 0.041$ & 0.96 \\
\hline
\end{tabular}

The power law can be seen as a superposition of two mechanisms controlling the drug transport: the drug diffusion and the particle modification. Values of $n$ between 0.43 and 0.85 obtained for spherical particles can be considered as indicative of the superposition of both phenomena. ${ }^{32}$ For the CIP3 formulation, values of $\mathrm{n}$ obtained at $\mathrm{pH} 5$ (closer to 0.43 compared to that obtained at $\mathrm{pH}$ 7.4) could be due to the higher proportion of CIP transport due to CIP diffusion than at $\mathrm{pH}$ 7.4. At $\mathrm{pH}$ 5, particle degradation should be faster than at $\mathrm{pH} 7.4$ and the drug diffusion is the limiting step. At $\mathrm{pH} 7.4$, particle degradation could be the limiting step controlling the CIP release process. 

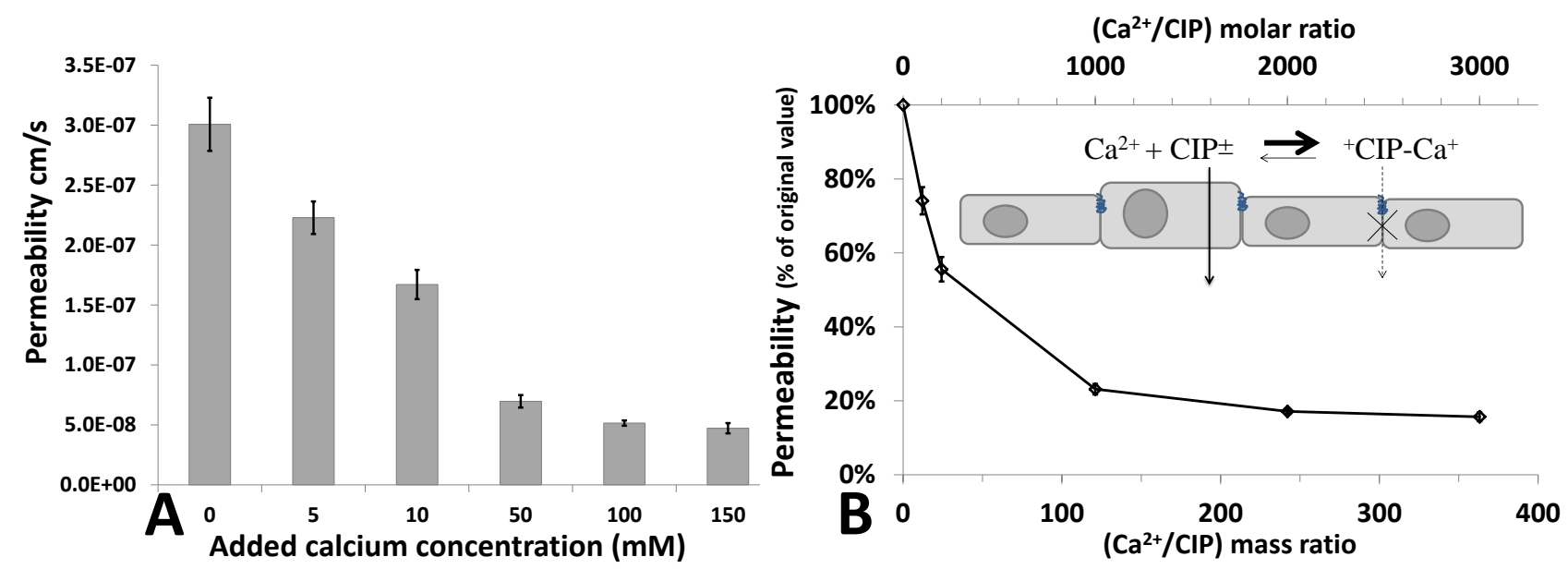

Figure 7: A) CIP apparent permeability versus concentration of added calcium, B) CIP apparent permeability in percent of the initial value (no added $\mathrm{Ca}^{2+}$ ) obtained for various $\mathrm{Ca}^{2+} / \mathrm{CIP}$ mass ratio. For all calcium concentration tested, fluorescein apparent permeability evaluated just after the CIP transport experiments was not significantly changed, suggesting the absence of cytotoxicity over the experimental time $(60 \mathrm{~min})$.

After landing in the lung, the particles will release CIP and CIP-calcium complexes, the active chemicals. To be efficient in the treatment of extracellular bacteria lung infection, such as $P$. Aeruginosa infection, these molecules released from the formulation have to stay in the lung extracellular fluid, i.e. they must have low lung-blood barrier permeability. Also, the effect of increasing calcium concentration on CIP apparent permeability has to be evaluated. Studies of CIP transport across pulmonary epithelium model Calu-3 were performed to evaluate the effect of calcium on CIP apparent permeability. Few studies have evaluated the transport of CIP across this model. ${ }^{16}$ A study measured the transport of CIP as a liposome formulation and, as expected, found out that the liposomes crossed the epithelial barrier less rapidly than the free CIP. ${ }^{56}$ CIP apparent permeability across Calu-3 cell monolayer decreased with an increase in calcium concentration in the transport medium (Fig. 7A). The interaction of one $\mathrm{CIP}^{ \pm}$with one $\mathrm{Ca}^{2+}$ should induce the formation of a charged molecular entity, " $\mathrm{CIP}^{+}-\mathrm{Ca}$ ", which should be less permeable across the Calu-3 cell monolayer than the free neutral CIP ${ }^{ \pm}$molecules.

For all calcium concentrations tested, fluorescein apparent permeability evaluated just after the CIP transport experiments was not significantly changed, showing that the cell monolayer integrity was maintained during the experiments. CIP apparent permeability values $(3.01 \pm$ 
$0.22 \times 10^{-7} \mathrm{~cm} / \mathrm{s}$ ) obtained with regular HBSS were consistent with previously reported values of $7.0 \pm 0.2 \times 10^{-7} \mathrm{~cm} / \mathrm{s} .{ }^{16}$ In figure $7 \mathrm{~B}$, the percentage of CIP apparent permeability decrease is plotted as a function of Ca:CIP mass ratio. In the presence of an apical CIP concentration of $0.0165 \mathrm{~g} / \mathrm{L}$, a first CIP apparent permeability decrease of $44.5 \pm 3.3 \%$ was observed for a $\mathrm{Ca}$ :CIP (w/w) ratio of 24:1 (Fig. 7B). A further increase in calcium concentration had a lesser effect on CIP apparent permeability and the maximal permeability decrease obtained of $84.3 \pm$ $1.16 \%$ was achieved in the presence of a Ca:CIP (w/w) ratio of 363:1. Likewise, a CIP apparent permeability decrease of $14 \%$ was observed across rat intestine in the presence of 5 $\mathrm{mM}$ of calcium. ${ }^{25}$ In these reported studies in rats the Ca:CIP (w/w) ratio was low $(0.12: 1)$ compared to the CIP transport experiment performed in the present study, but suggests that the $\mathrm{Ca}$ :CIP (w/w) ratio of $0.42: 1$ obtained in formulation CIP3 might be able to reduce CIP apparent permeability after inhalation. The interaction of one $\mathrm{CIP}^{ \pm}$with one $\mathrm{Ca}^{2+}$ in the particles, as suggested by the FTIR spectra analysis, should induce the release in the ELF of a bi-cationic molecular entity " $\mathrm{CIP}^{+}-\mathrm{Ca}^{+}$" (Figure 7B) which should be less permeable across the lung epithelium barrier than free CIP molecules. This apparent permeability decrease can mainly be attributed to the solubility decrease of the $\mathrm{CIP}^{+}-\mathrm{Ca}^{+}$bi-cationic complex in the epithelial cells phospholipid bilayer membranes compared to the solubility of the zwitterionic $\mathrm{CIP}^{ \pm}$. Additionally, in-vivo, the negatively charged mucins lining on the pulmonary epithelial cells could interact with the complex, thereby increasing CIP pulmonary half-life, as observed for tobramycin. ${ }^{61}$ 


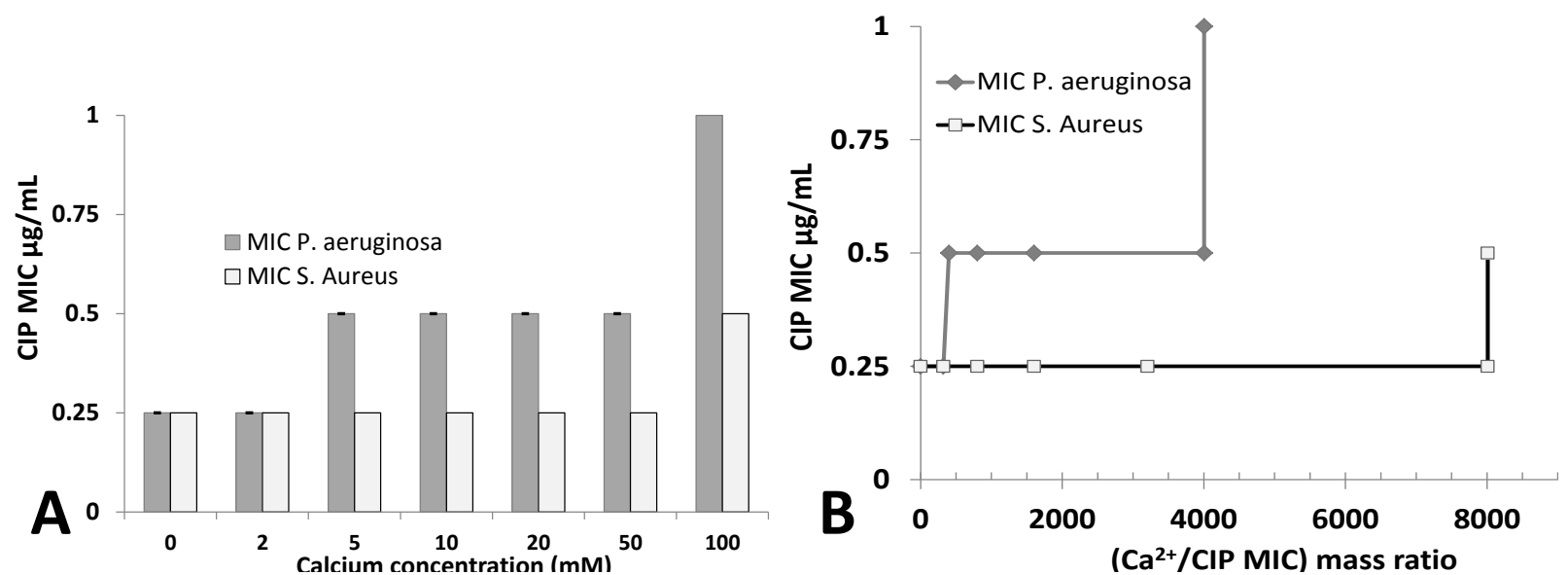

Figure 8: A) CIP apparent MIC against $P$. aeruginosa and $S$. Aureus measured in Mueller-Hinton medium having increasing calcium concentration. B) CIP apparent MIC against $P$. aeruginosa and $S$. Aureus versus $\mathrm{Ca}$ :CIP mass ratio. MICs represent non-continuous data and are accurate to only plus or minus one two-fold dilution.

Once in the pulmonary ELF, the CIP and CIP-calcium complexes released from the particles have to produce an antibacterial action. Thus, the effect of increasing calcium concentration on the antibacterial activity of CIP molecules has to be evaluated. Several studies evaluated the FQs activity against bacteria in the presence of cations. In most tests it was found that the activity of the complexes is comparable to free FQs. ${ }^{62,}{ }^{63}$ However some microbiological studies showed increases ${ }^{63,}{ }^{64}$ or decreases ${ }^{63}$ in the antibacterial activity of FQs. These phenomena depend on the $\mathrm{FQ}$, the cation and also the bacterial species used. We evaluated the effect of increasing calcium concentrations on the CIP potency by determining the CIP apparent MIC against $P$. aeruginosa and against $S$. aureus, CIP sensitive Gram negative and Gram positive bacteria, respectively (Fig. 8). These two bacterial species are the main causes of infection in patients with cystic fibrosis. ${ }^{1}$ In these experiments, no influence of the calcium alone on the two bacteria growth was observed at all used concentrations (data not shown). The MIC of CIP against $S$. Aureus was $0.25 \mu \mathrm{g} / \mathrm{mL}$. CIP in-vitro antimicrobial activity against S. Aureus was unchanged in the presence of increasing calcium concentration, up to a concentration of $50 \mathrm{mM}$, and then doubled in the presence of calcium at a concentration of 100 mM. In this condition, the Ca:CIP mass ratio was 8000 , much higher than the Ca:CIP mass ratio inducing the maximal decrease in CIP apparent permeability. CIP activity against $P$. 
Aeruginosa was more sensitive to calcium concentration increase than the CIP activity observed against S. Aureus. Anti- P. aeruginosa CIP apparent MIC was doubled in the presence of $5 \mathrm{mM}$ of calcium and increased further for $100 \mathrm{mM}$ of calcium. However, this increase in apparent MIC occurred for Ca:CIP ratios higher than that which induced the maximal decrease in CIP apparent permeability. Therefore, a maximal decrease in CIP apparent permeability can be obtained without any change in CIP antibacterial activity.

The fact that CIP activity against $P$. aeruginosa is more sensitive to calcium than its activity against $S$. aureus might occur because of the effective permeability barrier function of the outer membrane of the Gram negative bacteria. FQs are supposed to enter into Gram negative cells by diffusion across the outer membrane barrier and through porins. ${ }^{65}$ In the presence of high concentrations of $\mathrm{Ca}^{2+}$ the Gram negative bacteria outer membrane barrier is altered due to electrostatic interactions between the cation and the lipopolysaccharide present in this membrane, reducing its permeability. ${ }^{65}$ However, charged $\mathrm{CIP}^{+}-\mathrm{Ca}^{+}$complexes molecules are likely to pass through porin channels and accumulate in the periplasm due to the interiornegative Donnan potential across the outer membrane. ${ }^{66}$ This accumulation could lead to high cytoplasmic levels, as the cytoplasm equilibrates very rapidly with the periplasm, even for hydrophilic drugs. ${ }^{66}$

\section{Conclusions}

We demonstrated that inhalable inorganic-organic microparticles could be made of mineral calcium carbonate, calcium formate and biopolymer (HA) with adaptable properties to fulfil the pharmaceutical requirements of an aerosolisable powder. These particles were loaded with various amounts of CIP and varying CIP:calcium ratios. These particles enable CIP controlled release with low dependency on the $\mathrm{pH}$. In the presence of calcium the CIP apparent permeability across a pulmonary epithelium model was reduced by $84 \%$, while the CIP antibacterial activity was maintained. 


\section{Acknowledgements}

The authors acknowledge funding from the Ireland-France Ulysses research funding programme (Irish Research Council and Campus France) and from Science Foundation Ireland under grants nos. 07/SRC/B1154 and 12/RC/2275.

\section{References}

1. Geller, D. E. Aerosol Antibiotics in Cystic Fibrosis. Respiratory Care 2009, 54, (5), 658-670.

2. Novosad, S. A.; Barker, A. F. Chronic obstructive pulmonary disease and bronchiectasis. Current opinion in pulmonary medicine 2013, 19, (2), 133-139.

3. Marchand, S.; Gobin, P.; Brillault, J.; Baptista, S.; Adier, C.; Olivier, J.-C.; Mimoz, O.; Couet, W. Aerosol therapy with colistin methanesulfonate: a biopharmaceutical issue illustrated in rats. Antimicrobial agents and chemotherapy 2010, 54, (9), 3702-3707.

4. Gontijo, A. V. L.; Grégoire, N.; Lamarche, I.; Gobin, P.; Couet, W.; Marchand, S. Biopharmaceutical Characterization of Nebulized Antimicrobial Agents in Rats: 2. Colistin. Antimicrobial agents and chemotherapy 2014, 58, (7), 3950-3956.

5. Sugano, K.; Takata, N.; Machida, M.; Saitoh, K.; Terada, K. Prediction of passive intestinal absorption using bio-mimetic artificial membrane permeation assay and the paracellular pathway model. International journal of pharmaceutics 2002, 241, (2), 241-251.

6. Geller, D. E.; Konstan, M. W.; Smith, J.; Noonberg, S. B.; Conrad, C. Novel tobramycin inhalation powder in cystic fibrosis subjects: pharmacokinetics and safety. Pediatric pulmonology 2007, 42, (4), 307-313.

7. Fiel, S. B. Aerosolized antibiotics in cystic fibrosis: an update. Expert review of respiratory medicine 2014, 8, (3), 305-314.

8. Tewes, F.; Paluch, K. J.; Tajber, L.; Gulati, K.; Kalantri, D.; Ehrhardt, C.; Healy, A. M. Steroid/mucokinetic hybrid nanoporous microparticles for pulmonary drug delivery. European Journal of Pharmaceutics and Biopharmaceutics 2013, 85, (3), 604-613.

9. Healy, A. M.; Amaro, M. I.; Paluch, K. J.; Tajber, L. Dry powders for oral inhalation free of lactose carrier particles. Advanced drug delivery reviews 2014, 75, 32-52 .

10. Scully, B.; Nakatomi, M.; Ores, C.; Davidson, S.; Neu, H. Ciprofloxacin therapy in cystic fibrosis. The American journal of medicine 1987, 82, (4A), 196-201.

11. Stahlmann, R.; Lode, H. M. Risks associated with the therapeutic use of fluoroquinolones. Expert Opinion on Drug Safety 2013, 12, (4), 497-505.

12. Stephenson, A. L.; Wu, W.; Cortes, D.; Rochon, P. A. Tendon Injury and Fluoroquinolone Use: A Systematic Review. Drug Safety 2013, 36, (9), 709-721.

13. Guillot, E.; Sermet, I.; Ferroni, A.; Chhun, S.; Pons, G.; Zahar, J. R.; Jullien, V. Suboptimal ciprofloxacin dosing as a potential cause of decreased Pseudomonas aeruginosa susceptibility in children with cystic fibrosis. Pharmacotherapy: The Journal of Human Pharmacology and Drug Therapy 2010, 30, (12), 1252-1258.

14. Serisier, D. J.; Bilton, D.; De Soyza, A.; Thompson, P. J.; Kolbe, J.; Greville, H. W.; Cipolla, D.; Bruinenberg, P.; Gonda, I. Inhaled, dual release liposomal ciprofloxacin in non-cystic fibrosis bronchiectasis (ORBIT-2): a randomised, double-blind, placebo-controlled trial. Thorax 2013.

15. Stass, H.; Weimann, B.; Nagelschmitz, J.; Rolinck-Werninghaus, C.; Staab, D. Tolerability and pharmacokinetic properties of ciprofloxacin dry powder for inhalation in patients with cystic fibrosis: a Phase I, randomized, dose-escalation study. Clinical therapeutics 2013, 35, (10), 1571-1581.

16. Brillault, J.; De Castro, W. V.; Couet, W. Relative contributions of active mediated transport and passive diffusion of fluoroquinolones with various lipophilicities in a Calu-3 lung epithelial cell model. Antimicrob Agents Chemother 2010, 54, (1), 543-5. 
17. Gontijo, A. V. L.; Brillault, J.; Grégoire, N.; Lamarche, I.; Gobin, P.; Couet, W.; Marchand, S. Biopharmaceutical Characterization of Nebulized Antimicrobial Agents in Rats. 1. Ciprofloxacin, Moxifloxacin and Grepafloxacin. Antimicrobial agents and chemotherapy 2014, 58, (7), 3942-3949.

18. Wong, J. P.; Yang, H.; Blasetti, K. L.; Schnell, G.; Conley, J.; Schofield, L. N. Liposome delivery of ciprofloxacin against intracellular Francisella tularensis infection. Journal of Controlled Release 2003, 92, (3), 265-273.

19. Antoniu, S.; Azoicai, D. Ciprofloxacin DPI in non-cystic fibrosis bronchiectasis: a Phase II randomized study. Expert Opinion on Investigational Drugs 2013, 22, (5), 671-673.

20. Wilson, R.; Welte, T.; Polverino, E.; De Soyza, A.; Greville, H.; O'Donnell, A.; Alder, J.; Reimnitz, P.; Hampel, B. Ciprofloxacin dry powder for inhalation in non-cystic fibrosis bronchiectasis: a phase II randomised study. European Respiratory Journal 2013, 41, (5), 1107-1115.

21. Turel, I. The interactions of metal ions with quinolone antibacterial agents. Coordination Chemistry Reviews 2002, 232, (1), 27-47.

22. Uivarosi, V. Metal complexes of quinolone antibiotics and their applications: an update. Molecules 2013, 18, (9), 11153-11197.

23. Helena, M.; Teixeira, S. F.; Vilas-Boas, L. F.; Gil, V. M. S.; Teixeira, F. Complexes of Ciprofloxacin with Metal Ions Contained in Antacid Drugs. Journal of Chemotherapy 1995, 7, (2), 126132.

24. Navarro, A. S.; Cabarga, M. M.; Hurlé, A. D.-G. Comparative study of the influence of Ca2+ on absorption parameters of ciprofloxacin and ofloxacin. Journal of Antimicrobial Chemotherapy 1994, $34,(1), 119-125$.

25. Simon, Ž.; Katja, B.; Darko, U.; Marjan, V.; Albin, K. Metal cation-fluoroquinolone complexes do not permeate through the intestinal absorption barrier. Journal of Pharmaceutical and Biomedical Analysis 2010, 53, (3), 655-659.

26. Frost, R. W.; Lasseter, K.; Noe, A.; Shamblen, E.; Lettieri, J. Effects of aluminum hydroxide and calcium carbonate antacids on the bioavailability of ciprofloxacin. Antimicrobial agents and chemotherapy 1992, 36, (4), 830-832.

27. Dudley, M. N.; Berkley, N.; Griffith, D. C.; Loutit, J. S.; Morgan, E. E.; Bostian, K. A.; Sethi, S., Use of Aerosolized Antibiotics for Treating Chronic Obstructive Pulmonary Disease. Google Patents: 2012.

28. Caço, A. I.; Varanda, F.; Pratas de Melo, M. J.; Dias, A. M.; Dohrn, R.; Marrucho, I. M. Solubility of antibiotics in different solvents. Part II. Non-hydrochloride forms of tetracycline and ciprofloxacin. Industrial \& Engineering Chemistry Research 2008, 47, (21), 8083-8089.

29. Tewes, F.; Gobbo, O. L.; Amaro, M. I.; Tajber, L.; Corrigan, O. I.; Ehrhardt, C.; Healy, A. M. Evaluation of HP $\beta C D-P E G$ microparticles for salmon calcitonin administration via pulmonary delivery. Molecular Pharmaceutics 2011, 8, (5), 1887-1898.

30. Tewes, F.; Ehrhardt, C.; Healy, A. Superparamagnetic iron oxide nanoparticles (SPIONs)-loaded Trojan microparticles for targeted aerosol delivery to the lung. European Journal of Pharmaceutics and Biopharmaceutics 2013, 86, (1), 98-104.

31. Breda, S. A.; Jimenez-Kairuz, A. F.; Manzo, R. H.; Olivera, M. E. Solubility behavior and biopharmaceutical classification of novel high-solubility ciprofloxacin and norfloxacin pharmaceutical derivatives. International journal of pharmaceutics 2009, 371, (1), 106-113.

32. Siepmann, J.; Peppas, N. Modeling of drug release from delivery systems based on hydroxypropyl methylcellulose (HPMC). Advanced drug delivery reviews 2001, 48, (2), 139-157.

33. Brillault, J.; De Castro, W. V.; Harnois, T.; Kitzis, A.; Olivier, J. C.; Couet, W. P-glycoproteinmediated transport of moxifloxacin in a Calu-3 lung epithelial cell model. Antimicrob Agents Chemother 2009, 53, (4), 1457-62.

34. Tewes, F.; Brillault, J.; Couet, W.; Olivier, J. C. Formulation of rifampicin-cyclodextrin complexes for lung nebulization. J. Control. Release 2008, 129, (2), 93-99. 
35. Arias, J. L.; Fernández, M. a. S. Polysaccharides and Proteoglycans in Calcium Carbonate-based Biomineralization. Chemical Reviews 2008, 108, (11), 4475-4482.

36. M.-K. Tran, L. N. H., B. Calvignac, T. Beuvier, F. Tewes, G.J.-R. Delcroix, F. Hindré, F. Boury. Lysozyme encapsulation within PLGA and $\mathrm{CaCO} 3$ microparticles using supercritical $\mathrm{CO} 2$ medium. The Journal of Supercritical Fluids 2013, 79, 159-169.

37. Ros, M.; Casciaro, R.; Lucca, F.; Troiani, P.; Salonini, E.; Favilli, F.; Quattrucci, S.; Sher, D.; Assael, B. M. Hyaluronic Acid Improves the Tolerability of Hypertonic Saline in the Chronic Treatment of Cystic Fibrosis Patients: A Multicenter, Randomized, Controlled Clinical Trial. Journal of aerosol medicine and pulmonary drug delivery 2014, 27, (2), 133-137.

38. Turino, G. M.; Cantor, J. O. Hyaluronan in Respiratory Injury and Repair. American Journal of Respiratory and Critical Care Medicine 2003, 167, (9), 1169-1175.

39. Aranaz, I.; Gutiérrez, M.; Yuste, L.; Rojo, F.; Ferrer, M.; Del Monte, F. Controlled formation of the anhydrous polymorph of ciprofloxacin crystals embedded within chitosan scaffolds: study of the kinetic release dependence on crystal size. Journal of Materials Chemistry 2009, 19, (11), 1576-1582.

40. Li, X.; Zhi, F.; Hu, Y. Investigation of excipient and processing on solid phase transformation and dissolution of ciprofloxacin. International Journal of Pharmaceutics 2007, 328, (2), 177-182.

41. Matahwa, H.; Ramiah, V.; Sanderson, R. D. Calcium carbonate crystallization in the presence of modified polysaccharides and linear polymeric additives. Journal of Crystal Growth 2008, 310, (21), 4561-4569.

42. Ridha, F. N.; Manovic, V.; Wu, Y.; Macchi, A.; Anthony, E. J. Post-combustion CO2 capture by formic acid-modified CaO-based sorbents. International Journal of Greenhouse Gas Control 2013, 16, (0), 21-28.

43. Yokohira, M.; Kuno, T.; Yamakawa, K.; Hosokawa, K.; Matsuda, Y.; Hashimoto, N.; Suzuki, S.; Saoo, K.; Imaida, K. Lung toxicity of 16 fine particles on intratracheal instillation in a bioassay model using f344 male rats. Toxicologic pathology 2008, 36, (4), 620-631.

44. Arold, S. P.; Berry, E. L.; Rosa, D.; Saia, F. A.; Kong, S.; Wright, P. L.; Clarke, R. W.; Hava, D. L. Inhaled cationic salts modulate macrophage function to reduce inflammation during LPS induced lung injury. European Respiratory Journal 2012, 40, (Suppl 56).

45. Turel, I.; Bukovec, P.; Quirós, M. Crystal structure of ciprofloxacin hexahydrate and its characterization. International Journal of Pharmaceutics 1997, 152, (1), 59-65.

46. Al-Hosney, H. A.; Carlos-Cuellar, S.; Baltrusaitis, J.; Grassian, V. H. Heterogeneous uptake and reactivity of formic acid on calcium carbonate particles: a Knudsen cell reactor, FTIR and SEM study. Physical Chemistry Chemical Physics 2005, 7, (20), 3587-3595.

47. Politi, Y.; Arad, T.; Klein, E.; Weiner, S.; Addadi, L. Sea urchin spine calcite forms via a transient amorphous calcium carbonate phase. Science 2004, 306, (5699), 1161-1164.

48. Al-Sawalmih, A.; Li, C.; Siegel, S.; Fratzl, P.; Paris, O. On the stability of amorphous minerals in lobster cuticle. Advanced Materials 2009, 21, (40), 4011-4015.

49. Gu, C.; Karthikeyan, K. G. Sorption of the Antimicrobial Ciprofloxacin To Aluminum and Iron Hydrous Oxides. Environmental Science \& Technology 2005, 39, (23), 9166-9173.

50. Wu, G.; Wang, G.; Fu, X.; Zhu, L. Synthesis, crystal structure, stacking effect and antibacterial studies of a novel quaternary copper (II) complex with quinolone. Molecules 2003, 8, (2), 287-296.

51. Meiron, O. E.; Bar-David, E.; Aflalo, E. D.; Shechter, A.; Stepensky, D.; Berman, A.; Sagi, A. Solubility and Bioavailability of Stabilized Amorphous Calcium Carbonate. J. Bone Miner. Res. 2011, 26, (2), 364-372.

52. Newell, H. E.; Buckton, G.; Butler, D. A.; Thielmann, F.; Williams, D. R. The use of inverse phase gas chromatography to measure the surface energy of crystalline, amorphous, and recently milled lactose. Pharmaceutical research 2001, 18, (5), 662-666. 
53. Zhang, J.; Ebbens, S.; Chen, X.; Jin, Z.; Luk, S.; Madden, C.; Patel, N.; Roberts, C. J. Determination of the surface free energy of crystalline and amorphous lactose by atomic force microscopy adhesion measurement. Pharmaceutical research 2006, 23, (2), 401-407.

54. Amaro, M. I.; Tajber, L.; Corrigan, O. I.; Healy, A. M. Optimisation of spray drying process conditions for sugar nanoporous microparticles (NPMPs) intended for inhalation. International Journal of Pharmaceutics 2011, 421, (1), 99-109.

55. Carvalho, T. C.; Peters, J. I.; Williams lii, R. O. Influence of particle size on regional lung deposition - What evidence is there? International Journal of Pharmaceutics 2011, 406, (1-2), 1-10.

56. Ong, H. X.; Benaouda, F.; Traini, D.; Cipolla, D.; Gonda, I.; Bebawy, M.; Forbes, B.; Young, P. M. In vitro and ex vivo methods predict the enhanced lung residence time of liposomal ciprofloxacin formulations for nebulisation. European Journal of Pharmaceutics and Biopharmaceutics 2014, 86, (1), 83-89.

57. Cipolla, D.; Wu, H.; Eastman, S.; Redelmeier, T.; Gonda, I.; Chan, H.-K. Development and Characterization of an In Vitro Release Assay for Liposomal Ciprofloxacin for Inhalation. Journal of Pharmaceutical Sciences 2014, 103, (1), 314-327.

58. Cipolla, D.; Wu, H.; Gonda, I.; Chan, H.-K. Aerosol Performance and Long-Term Stability of Surfactant-Associated Liposomal Ciprofloxacin Formulations with Modified Encapsulation and Release Properties. AAPS PharmSciTech 2014, 15, (5), 1218-1227.

59. Ching, A. L.; Liew, C. V.; Chan, L. W.; Heng, P. W. S. Modifying matrix micro-environmental pH to achieve sustained drug release from highly laminating alginate matrices. European Journal of Pharmaceutical Sciences 2008, 33, (4-5), 361-370.

60. Pezzulo, A. A.; Tang, X. X.; Hoegger, M. J.; Alaiwa, M. H. A.; Ramachandran, S.; Moninger, T. O.; Karp, P. H.; Wohlford-Lenane, C. L.; Haagsman, H. P.; van Eijk, M. Reduced airway surface pH impairs bacterial killing in the porcine cystic fibrosis lung. Nature 2012, 487, (7405), 109-113.

61. Stockmann, C.; Roberts, J. K.; Yellepeddi, V. K.; Sherwin, C. M. Clinical Pharmacokinetics of Inhaled Antimicrobials. Clinical pharmacokinetics 2015, 54, (5), 473-492.

62. Drevenšek, P.; Košmrlj, J.; Giester, G.; Skauge, T.; Sletten, E.; Sepčić, K.; Turel, I. X-Ray crystallographic, NMR and antimicrobial activity studies of magnesium complexes of fluoroquinolones - racemic ofloxacin and its S-form, levofloxacin. Journal of Inorganic Biochemistry 2006, 100, (11), 1755-1763.

63. Feio, M. J.; Sousa, I.; Ferreira, M.; Cunha-Silva, L.; Saraiva, R. G.; Queirós, C.; Alexandre, J. G.; Claro, V.; Mendes, A.; Ortiz, R. Fluoroquinolone-metal complexes: a route to counteract bacterial resistance? Journal of Inorganic Biochemistry 2014, 138, 129-143.

64. Efthimiadou, E. K.; Sanakis, Y.; Katsarou, M.; Raptopoulou, C. P.; Karaliota, A.; Katsaros, N.; Psomas, G. Neutral and cationic mononuclear copper(II) complexes with enrofloxacin: structure and biological activity. J Inorg Biochem 2006, 100, (8), 1378-88.

65. Delcour, A. H. Outer membrane permeability and antibiotic resistance. Biochimica et Biophysica Acta (BBA) - Proteins and Proteomics 2009, 1794, (5), 808-816.

66. Nikaido, H.; Thanassi, D. Penetration of lipophilic agents with multiple protonation sites into bacterial cells: tetracyclines and fluoroquinolones as examples. Antimicrobial agents and chemotherapy 1993, 37, (7), 1393. 